\title{
EL ARMAMENTO DE LA NECRÓPOLIS IBÉRICA DE LA SERRETA DE ALCOI (ALICANTE, ESPAÑA)
}

\author{
POR
}

\author{
CRISTINA REIG SEGUÍ
}

\section{RESUMEN - ABSTRACT}

En este artículo se presenta el armamento recuperado en la necrópolis ibérica de La Serreta, cuya cronología se establece desde principios del s. IV a.C. hasta mediados del s. III a.C., estudiándose sus características formales, clasificación, tipología y variantes, deposición en el área de la sepultura, frecuencia de aparición de las diferentes categorías y sus distintas asociaciones.

A través del análisis de las asociaciones de armas, se pretende descubrir si dichos conjuntos resultan funcionalmente operativos o por el contrario su deposición en los ajuares es aleatoria.

In this paper we present the weapons recovered in the Iberian necropolis of La Serreta at Alcoi (Alicante, Spain), dated between the fourth century and the first half of the third century before Christ. We study the formal characteristics, classification, typology and variants, deposition in the burial area, frequency of appearance of the different categories and their associations.

Through the analysis of weapon associations we try to discover if these assemblages are functionally operative or in the other hand, the depositions are fortuitous.

\section{PALABRAS CLAVE - KEY WORDS}

Armamento ibérico. Necrópolis. La Serreta. Panoplias.

Iberian weapons. Necropolis. La Serreta of Alcoi. Panoply.

\section{INTRODUCCIÓN}

El yacimiento ibérico de La Serreta se encuentra en un elevado cerro, (1.050 m. s.n.m. de altura máxima en la cumbre) alineado de $\mathrm{NE}$ a SW, situado en el centro de la comarca de l'Alcoià-Comtat, al norte de la provincia de Alicante, en el corazón de la región que las fuentes clásicas denominan Contestania. Su estratégica situación proporciona un inmejorable control del territorio circundante, al dominar las tierras de labor que se extienden a sus pies, así como las vías de comunicación entre las tierras del interior y la costa (fig. 1).

El emplazamiento consta de tres áreas: poblado y santuario, descubiertos en 1917, y la necrópolis descubierta en 1987.

El poblado se sitúa en la cumbre y su ladera sur, adaptándose a la orografía del terreno y aprovechando al máximo las pequeñas terrazas escalonadas, delimitadas por abruptos escarpes rocosos (Llobregat et alii, 1992). 


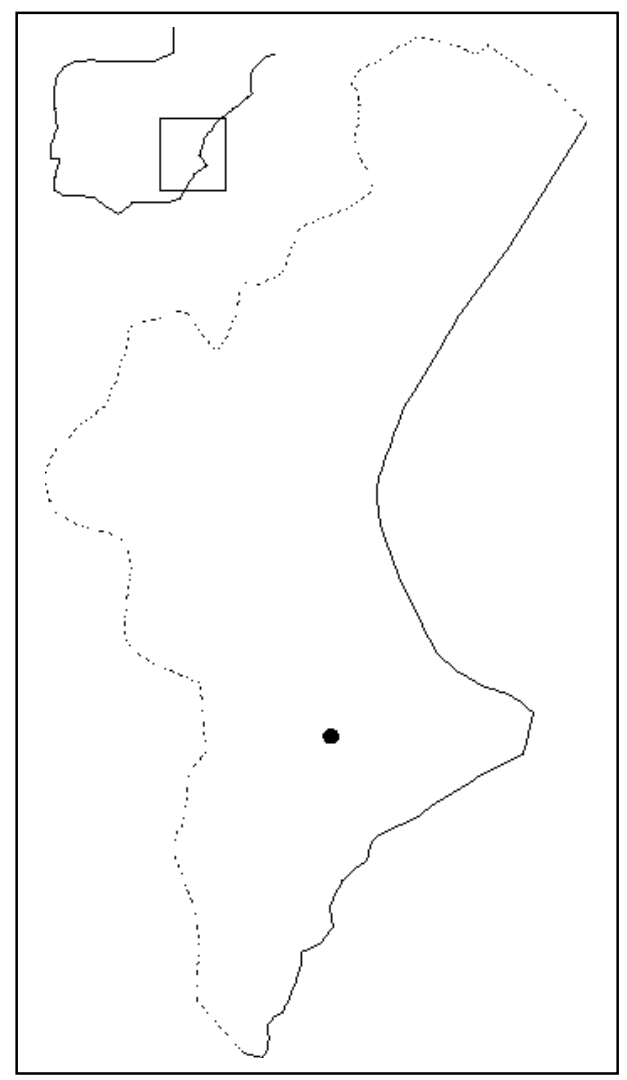

Fig. 1. Localización geográfica del yacimiento ibérico de La Serreta (Alcoy, Alicante).

Una muralla circunda el poblado, abriéndose en su parte este una puerta de acceso, protegida por una torre maciza en forma de proa de nave (Llobregat et alii, 1995).

Las últimas campañas de excavación sitúan la extensión del poblado en torno a las 5,5 ha en planta (Olcina et alii, 1998: 37).

La cronología del asentamiento abarca desde el s. IV a.C. a inicios del s. II a.C. No obstante, el poblado que conocemos, urbanísticamente y por los materiales arqueológicos recuperados, corresponde a la última fase de su existencia, entre mediados del s. III e inicios del s. II a.C. (Grau Mira, 1996; Olcina et alii, 1998). Respecto al primer período de existencia, centrado en el s. IV a.C., la información de que disponemos es la proporcionada por los niveles de relleno (Tarradell, 1968) que permiten identificar su ubicación en la parte más elevada del cerro. A esta primera fase del poblado, previa a la expansión posterior del s. III a.C. (Olcina et alii, 1998), corresponde la necrópolis estudiada (Cortell et alii, 1992; Moltó y Reig, 1996).

Entre el material arqueológico procedente del poblado, destacan los numerosos textos ibéricos escritos sobre lámina de plomo, y la vajilla con rica decoración figurada.

El área del santuario se localiza en la parte más alta del poblado, en su extremo occidental, en cuyas inmediatas laderas se encontraron numerosos exvotos ibéricos de terracota y materiales de construcción romanos. Este lugar de culto estaría vigente durante el s. III a.C., como se deduce de la cronología de los exvotos (Juan, 1988:329), perdurando tras la desaparición del poblado de manera intermitente, puesto que se descubren materiales utilizados como exvotos, tales como terra sigillata y monedas, que indican frecuentación pero no habitación extensa y estable. 
La necrópolis se localiza al E del cuerpo sur de la puerta del poblado, en la parte oriental del cerro, a escasos metros de la muralla y en las inmediaciones del camino que conduce al asentamiento.

Se trata de una necrópolis con incineraciones secundarias, depositadas en hoyos practicados en la roca y con restos de superestructuras. El lugar o lugares de cremación de los cadáveres y su ajuar no ha sido localizado por el momento. Los restos de la cremación se depositan en urnas junto a los elementos del ajuar o bien directamente sobre la roca, mezclados entre los demás objetos.

Los ajuares funerarios hallados en las sepulturas constan de cerámica ibérica, cerámica de importación, piezas de ornamento y armas, siendo éstas abundantes y de excepcional interés, por su riqueza y variedad.

Del estudio de los materiales se desprende un uso de la necrópolis que abarca el s. IV y la primera mitad del s. III a.C.

\section{El ARMAMENTO}

\section{II. a. Armas ofensivas cortas}

\section{II. a. 1. Falcatas}

Del total de 80 sepulturas excavadas hasta 1997, 29 de ellas cuentan con armamento, lo que representa el $36 \%$ de las sepulturas excavadas, y de éstas, 22 aportan falcata, (27,5\% del total de sepulturas, $76 \%$ del total de sepulturas con armamento), entera o fragmentada.

Salvo en dos casos, donde además de una falcata entera aparecen fragmentos de otra, lo habitual hasta la fecha es la aparición de una sola falcata por sepultura.

En la mayoría de los casos, 18 sepulturas, la falcata aparece asociada a otras armas, y sólo en cuatro sepulturas aparece como arma única: en la sepultura 15, que cuenta con fragmentos de otra falcata entre el ajuar, sin otro tipo de arma; la sepultura 22, un caso incierto ya que fue expoliada por clandestinos que sólo dejaron entre las tierras removidas fragmentos de hoja de falcata; la sepultura 43 , cuenta con una falcata fragmentada como único elemento de armamento; y la sepultura 74, donde la presencia de armas queda reducida a una cartela decorada con damasquinados de plata y fragmentos de vaina.

De las 22 sepulturas que aportan falcata contamos con 14 que presentan piezas lo suficientemente enteras para ser sometidas a estudio, en las restantes el estado de la pieza no puede aportar datos a efectos de estudio.

\section{MORFOLOGÍA}

\section{- EMPUÑADURA}

De las 14 falcatas mejor conservadas, 8 conservan la empuñadura: 4 de cabeza de ave, tipo A de Quesada (sepulturas 4, 11, 15 y 31) y 4 de cabeza de caballo, tipo B (sepulturas 1 , 27, 41y 53). Las 6 restantes presentan la empuñadura incompleta, tipo C (sepulturas 6, 20, $45,67,70$ y 72$)$.

- Cabeza de ave. Tipo A.

De las 4 empuñaduras tipo A, dos presentan guarda lateral de barra maciza, las correspondientes a las falcatas de las sepulturas 4 y 31 . Ésta última es una finísima barrita de sección circular con decoración en espiral en los $2 / 3$ de su longitud, y un engrosamiento discoidal antes de su unión con el pico del ave (lám. I). 


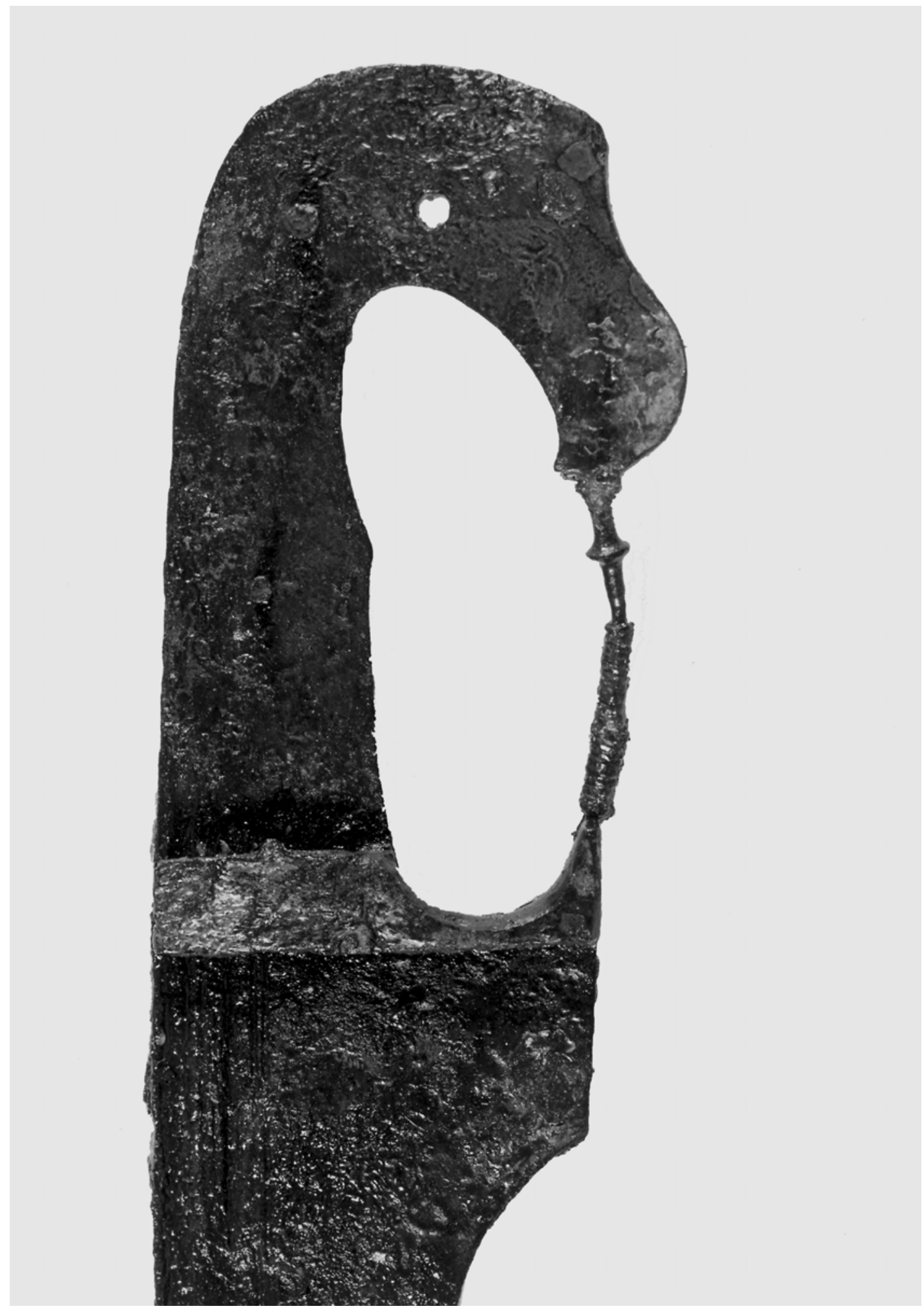

Lám. I. Empuñadura tipo A. Sepultura 31. 


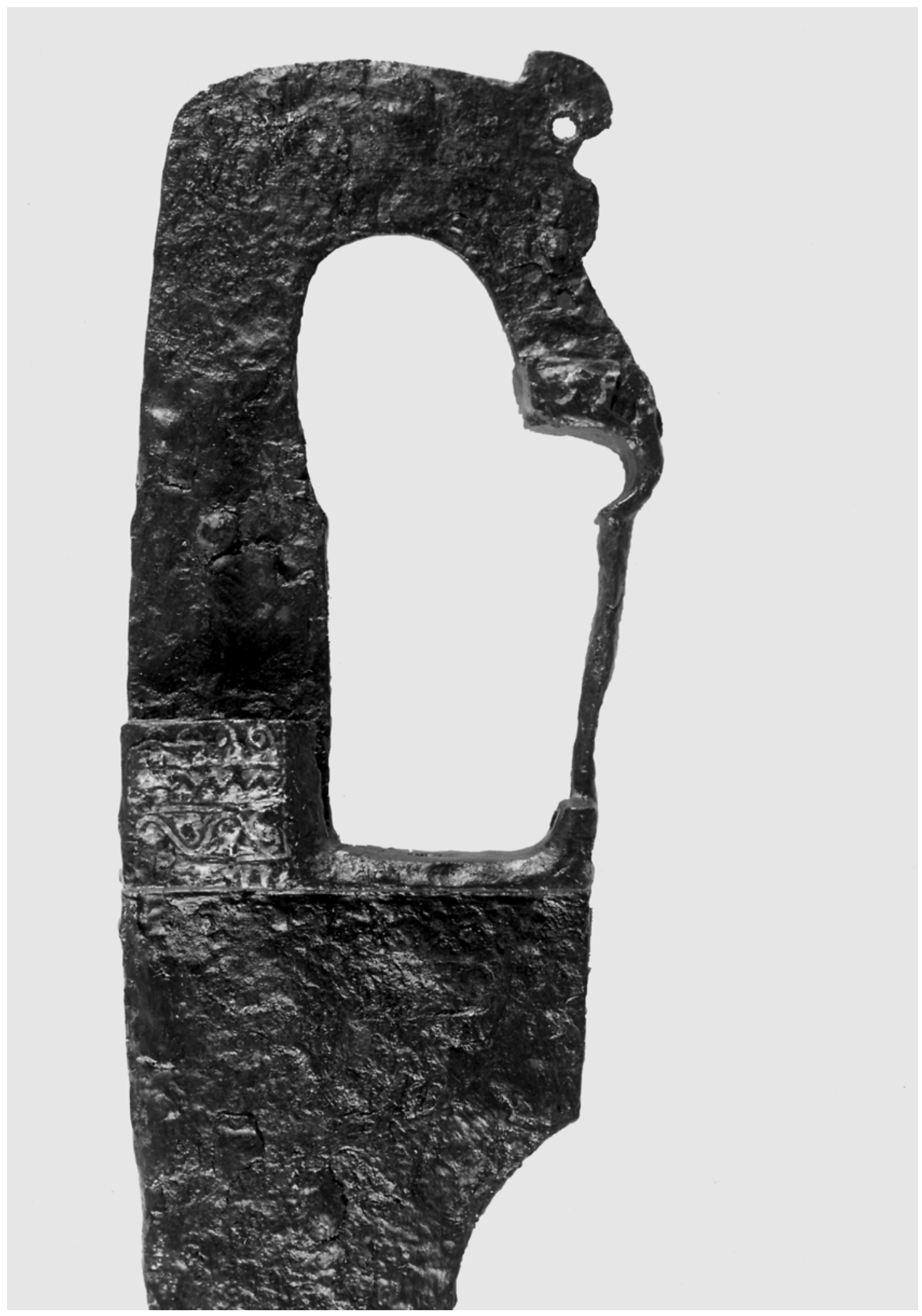

Lám. II. Empuñadura tipo B. Sepultura 27. 
En los dos casos restantes, la guarda lateral no se ha conservado.

La guarda basal que se asocia a este tipo de empuñadura parece ser, en todos los casos, el C-1 de Cuadrado, (Cuadrado, 1989: 20), que corresponde a una pequeña cartela, una escotadura semicircular más o menos abierta, y un apéndice ligeramente más alto que la cartela. Solamente la guarda correspondiente a la falcata de la sepultura 31 muestra una variante: del centro de la cartela parte un pequeño apéndice decorativo que quedaría sobre las cachas de la empuñadura.

Los remaches para la sujeción de las cachas se han conservado de forma muy desigual, oscilando entre 1 y 3 . Todos ellos se reducen a simples vástagos de hierro, con ligero engrosamiento en la cabeza en el caso de los mejor conservados.

Las acanaladuras bajo la empuñadura se asocian en tres casos al tipo 2, de acanaladuras paralelas. En la falcata de la sepultura 15 el estado de la pieza no permite distinguir claramente a qué tipo pueden corresponder (tipo 0 ).

Si estudiamos la cuestión desde la perspectiva del total de falcatas que presentan acanaladuras tipo 2, contamos con ocho falcatas, de las cuales tres se asocian a empuñadura tipo A: sepulturas 4, 11 y 31 ; una presenta empuñadura tipo B: sep 41; y las restantes han perdido la empunadura: sepulturas 6, 20, 45 y 67. El resultado, por lo tanto, no varía.

Parece tentador llegar a la conclusión de que las empuñaduras de cabeza de ave se asocian prioritariamente a acanaladuras del tipo 2 , visto que esta premisa se cumple mayoritariamente; no obstante el reducido número de piezas hace que esta asociación tenga el valor de confirmación de una tendencia más que de conclusión definitiva (Quesada, 1997: 95).

- Cabeza de caballo. Tipo B.

Las falcatas de las sepulturas 1, 27, 41 y 53 han conservado sus empuñaduras tipo B, de cabeza de caballo, presentando siempre guarda lateral de barra maciza.

En las falcatas de las sepulturas 1 y 27 el hocico del caballo presenta una sección engrosada y una prolongación curva desde la que nace la barra maciza, conformando la guarda lateral, que apoya sobre el apéndice de la guarda basal (lám. II).

En la sepultura 41 toda la parte frontal de la cabeza de caballo es de sección circular, partiendo la guarda lateral del extremo mismo del hocico sin la prolongación curva que se advierte en los casos anteriores.

En la sepultura 53 la guarda lateral está formada por cabezas masculinas que están siendo tragadas por un animal. Esta pieza se estudia detenidamente más adelante, en el apartado de las armas decoradas.

No existe un único tipo de guarda basal para este tipo de empuñadura, ya que en la falcata de la sepultura 53 la guarda es del tipo A-1 de Cuadrado, el cual desarrolla una gran cartela decorada con damasquinados; la guarda de las falcatas procedentes de las sepulturas $27 \mathrm{y}$ 41 es del tipo B-2, con cartela mediana, también decoradas, y en la falcata de la sepultura 1 la guarda basal es del tipo $\mathrm{C}$, con cartela y apéndice de igual altura, con la escotadura rectangular, tipo $\mathrm{C}-3$.

Los remaches de sujeción de las cachas no se conservan enteros, en ocasiones no queda ni siquiera restos del vástago. Generalmente son de hierro y varían entre 1 y 3 .

No se aprecia una tendencia específica de asociación entre empuñadura del tipo B con un tipo determinado de acanaladuras bajo la guarda basal, ya que en dos casos las acanaladuras se abren en abanico, tipo 1, (sepulturas 27 y 53), en otro caso nacen paralelas bajo el puño, tipo 2, (sepultura 41), y en la sepultura 1 no es posible apreciar su disposición (tipo 0).

Invirtiendo la cuestión, y estudiando el total de falcatas que presentan acanaladuras divergentes, tipo 1, sólo tenemos dos casos, las de las sepulturas 27 y 53, las cuales son de empuñadura de cabeza de caballo. No obstante no creemos, por el escaso número de la 
muestra, que pueda asegurarse que este tipo de acanaladuras bajo el puño se asocien siempre a empuñaduras tipo B.

- Empuñadura incompleta. Tipo C.

Las falcatas de las sepulturas $6,20,45,67,70$ y 72 presentan una empuñadura tan fragmentada e incompleta que es imposible determinar a qué tipo corresponde, incluyéndose dentro del amplio tipo $\mathrm{C}$, de empuñadura indeterminada. Tampoco se han conservado las guardas laterales, sólo en el caso de la sepultura 72 se ha conservado la guarda lateral de barra maciza, suelta, sin unión a la empuñadura, que aparece incompleta.

La guarda basal también aparece muy deteriorada, en los tres casos en que es posible apreciarla, tratándose del tipo $\mathrm{C}$ de Cuadrado, con escotadura semicircular más o menos abierta.

No se han conservado restos de los remaches de sujeción de cachas, siendo únicamente la falcata de la sepultura 67 la que presenta remaches de bronce de cabeza estrellada.

Aunque estas falcatas no hayan conservado entera su empuñadura, la hoja en cambio sí permite analizar detalles como el arranque de las acanaladuras bajo el puño, que son paralelas (tipo 2) en cinco casos. Sólo en la falcata de la sepultura 72 el estado del metal impide apreciar siquiera si existen acanaladuras en esta zona.

\section{- Medidas - LIE}

El valor medio de la longitud total de las empuñaduras y la LIE (fig. 2) se sitúa en los valores ya observados para el conjunto de falcatas estudiadas por F. Quesada (1997, 103104): $11 \mathrm{~cm}$ para la empuñadura y $7.9 \mathrm{~cm}$ para la LIE, lo que confirma el hecho de que se trata de dimensiones prácticamente constantes en todas las falcatas.

Las falcatas de las sepulturas 53 y 67 aportan las empuñaduras más largas: $12 \mathrm{~cm}$, frente al arma de la sepultura 41 que cuenta con la más corta: $9,4 \mathrm{~cm}$.

Los valores que recogen las LIE son más regulares todavía: apenas $1 \mathrm{~cm}$ de diferencia en-

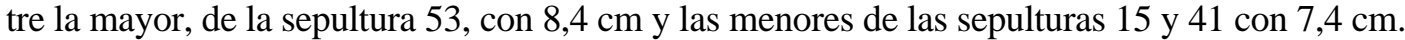

No existe relación entre la longitud total de la empuñadura y la LIE, ya que podemos observar en el cuadro que a mayor longitud total no necesariamente corresponde una LIE mayor, por ejemplo en la sepultura 67. Tampoco una LIE corta corresponde a una empuñadura pequeña, como ocurre en la sepultura 15.

\section{- HOJA}

La longitud de la hoja es el criterio fundamental para establecer diferencias de tamaño, ya que como hemos visto más arriba, la empuñadura es una dimensión que permanece constante, con una variación de pocos $\mathrm{cm}$.

En el primer cuadro (fig. 2) se recogen las dimensiones de las falcatas enteras, con las longitudes de cada una de las partes del arma. En el cuadro siguiente (fig. 3) se han añadido aquellas piezas que, aún no estando completas ${ }^{1}$, pueden aportar longitudes totales de partes

1 Las longitudes marcadas con asterisco indican aquellas longitudes conservadas, incompletas en pocos centímetros, pero que se han incluido en el cuadro ya que no modifican los valores medios ni los absolutos. Incluso restituyendo sobre dibujo los centímetros que le faltan a la pieza y añadiendo el valor obtenido, posiblemente real, pero objetivamente hipotético, hemos comprobado que no se alteran los resultados. Por lo tanto se ha decidido plasmar en el cuadro las medidas reales conservadas. 


\begin{tabular}{|c|c|c|c|c|c|c|c|c|}
\hline \multirow{2}{*}{ Sep. } & \multicolumn{7}{|c|}{ MEDIDAS DE LAS FALCATAS COMPLETAS } \\
\cline { 2 - 10 } & $\begin{array}{c}\text { Long. } \\
\text { máx. }\end{array}$ & $\begin{array}{c}\text { Long. } \\
\text { hoja }\end{array}$ & Ancho máx. & Ancho mín. & $\begin{array}{c}\text { Ángulo } \\
\text { axial }\end{array}$ & $\begin{array}{c}\text { Filo } \\
\text { dorsal }\end{array}$ & Long. emp. & LIE \\
\hline 1 & 64 & 52,5 & 6 & 4,5 & 71 & & 11,5 & 7,5 \\
\hline 4 & 62 & 50,5 & 6 & 4,5 & 74 & & 11,5 & 8,2 \\
\hline 15 & 57,5 & 46,5 & 6,2 & 3,8 & 77 & 20 & 11 & 7,4 \\
\hline 27 & 56 & 45,5 & 5,7 & 3,3 & 66 & 24,3 & 10,5 & 7,6 \\
\hline 31 & 56,8 & 45,6 & 5,6 & 3,4 & 73 & 24,6 & 11 & 8 \\
\hline 41 & 67,4 & 58 & 6,4 & 4,2 & 58 & & 9,4 & 7,4 \\
\hline 53 & 64 & 52,5 & 6,3 & 3,8 & 70 & 28 & 12 & 8,4 \\
\hline 67 & 63 & 51 & 5,5 & 4,4 & 84 & & 12 & 7,8 \\
\hline Promd & $\mathbf{6 1}$ & $\mathbf{5 0}$ & $\mathbf{6}$ & $\mathbf{4}$ & $\mathbf{7 2}$ & $\mathbf{2 4}$ & $\mathbf{1 1}$ & $\mathbf{8}$ \\
\hline
\end{tabular}

Fig. 2. Cuadro con las longitudes de cada una de las partes de las falcatas enteras.

\begin{tabular}{|c|c|c|c|c|c|c|c|c|}
\hline \multirow{2}{*}{ Sep. } & \multicolumn{6}{|c|}{ MEDIDAS DE LAS FALCATAS INCLUYENDO LONGITUDES COMPLETAS } \\
\cline { 2 - 10 } & $\begin{array}{c}\text { Long. } \\
\text { máx. }\end{array}$ & $\begin{array}{c}\text { Long. } \\
\text { hoja }\end{array}$ & Ancho máx. & Ancho mín. & $\begin{array}{c}\text { Ángulo } \\
\text { axial }\end{array}$ & $\begin{array}{c}\text { Filo } \\
\text { dorsal }\end{array}$ & Long. emp. & LIE \\
\hline 1 & 64 & 52,5 & 6 & 4,5 & 71 & & 11,5 & 7,5 \\
\hline 4 & 62 & 50,5 & 6 & 4,5 & 74 & & 11,5 & 8,2 \\
\hline 6 & & & 5,6 & 3,6 & 86 & & & \\
\hline 11 & $54,5^{*}$ & $44^{*}$ & 6 & 3,2 & 76 & $23^{*}$ & 10,5 & 7,6 \\
\hline 15 & 57,5 & 46,5 & 6,2 & 3,8 & 77 & 20 & 11 & 7,4 \\
\hline 20 & & 43,5 & 5 & 3,4 & 77 & & & \\
\hline 27 & 56 & 45,5 & 5,7 & 3,3 & 66 & 24,3 & 10,5 & 7,6 \\
\hline 31 & 56,8 & 45,6 & 5,6 & 3,4 & 73 & 24,6 & 11 & 8 \\
\hline 41 & 67,4 & 58 & 6,4 & 4,2 & 58 & & 9,4 & 7,4 \\
\hline 45 & & 48,5 & 6 & 3,3 & 83 & 28,5 & & \\
\hline 53 & 64 & 52,5 & 6,3 & 3,8 & 70 & 28 & 12 & 8,4 \\
\hline 67 & 63 & 51 & 5,5 & 4,4 & 84 & & 12 & 7,8 \\
\hline 70 & & & 6 & 3,5 & & & & \\
\hline 72 & $53^{*}$ & $47^{*}$ & 6,2 & 4 & 58 & $20,5^{*}$ & & \\
\hline Promd & $\mathbf{6 1}$ & $\mathbf{4 9}$ & $\mathbf{6}$ & $\mathbf{4}$ & $\mathbf{7 3}$ & $\mathbf{2 5}$ & $\mathbf{1 1}$ & $\mathbf{8}$ \\
\hline
\end{tabular}

Fig. 3. Cuadro con las longitudes de todas las falcatas y promedios obtenidos.

bien conservadas. Se observa que entre este último grupo lo que falta es la empuñadura, pero la hoja se ha conservado en buenas condiciones, lo cual nos permite disponer de más datos para estudiar las longitudes, anchos máximos y mínimos, ángulo axial y longitudes de filo dorsal.

Lo primero que llama la atención es lo poco que varían los valores medios obtenidos en el primer cuadro, elaborado con piezas completas, respecto del segundo, una vez añadidos valores totales de otras partes completas de armas incompletas. Esto nos indica que existe una regularidad en el tamaño del conjunto de armas procedentes de la necrópolis, sin que existan grandes desviaciones. 
La longitud media es de $61 \mathrm{~cm}$, valor que se aproxima bastante al $60,2 \mathrm{~cm}$ de media obtenido hasta la fecha (Quesada, 1997: 85, fig. 24). Como valor máximo aparece la falcata de la sepultura $41 \mathrm{con} 67,4 \mathrm{~cm}$ de longitud total, de los cuales $58 \mathrm{~cm}$ corresponden a la hoja, la más larga, lo que confirma la absoluta correlación existente entre longitud total de arma y longitud de hoja.

La más corta del conjunto de armas completas es la de la sepultura 27 , con $56 \mathrm{~cm}$ de longitud total y 45,5 de longitud de hoja, esto es, la hoja más corta del conjunto.

La media de la longitud de hoja en este conjunto es de $50 \mathrm{~cm}$, pero una vez incluidas la hoja de la sepultura 20 , realmente corta con sólo $43,5 \mathrm{~cm}$, y la de la 72 , de $47 \mathrm{~cm}$, el valor medio desciende a $49 \mathrm{~cm}$, muy próximo al $48,9 \mathrm{~cm}$ obtenido por el mismo autor.

$\mathrm{Si}$, como hemos visto antes, la longitud de empuñadura permanece casi constante y es la hoja la parte del arma que registra más variaciones, en realidad la falcata más corta con que contamos es la procedente de la sepultura 20, con la hoja más corta del cuadro segundo, la cual, pese a haber perdido la empuñadura no debería medir más de $55 \mathrm{~cm}$, suponiéndole un máximo de empuñadura de $12 \mathrm{~cm}$, máximo que presentan algunas de nuestras armas.

También los valores medios obtenidos de la máxima anchura y la mínima, 6 y $4 \mathrm{~cm}$, se acercan a los datos ya apuntados por el mencionado autor, 5,8 y $3,75 \mathrm{~cm}$.

La falcata de la sepultura 41, la más larga, es la que presenta un ancho máximo mayor: $6,4 \mathrm{~cm}$, lo que es lógico, ya que esta longitud admite la posibilidad de presentar un ligero aumento en su anchura. También el ancho mínimo que presenta esta hoja, 4,2 cm, está cerca del valor máximo con que contamos: $4,5 \mathrm{~cm}$ para las hojas largas de las sepulturas 1 y 4 .

El valor mínimo entre el ancho máximo de hoja es el de la falcata de la sepultura 20, con $5 \mathrm{~cm}$, que ha resultado ser la más corta, que a su vez presenta un ancho mínimo de $3,4 \mathrm{~cm}$, valor muy cercano a los $3,2 \mathrm{~cm}$, mínimo que presenta la falcata incompleta de la sepultura 11 , o los 3,3 cm de las hojas cortas de las sepulturas 27 o 45 .

Parece desprenderse de todos estos datos que existe una tendencia a que las armas largas admitan valores máximos, que no obstante no se alejan nunca demasiado de la media, sin perder sus proporciones. Y a la inversa, las armas cortas presentan valores mínimos en sus proporciones, valores que tampoco están lejos de la media.

- Filo dorsal.

El filo en el tercio distal del dorso que presentan algunas falcatas les confiere capacidad punzante además de la cortante que les proporciona el filo principal. De las falcatas que venimos estudiando, cinco no presentan este doble filo, su dorso es plano, y corresponden a las sepulturas 1, 4, 20, 41 y 67; y el resto tienen el filo dorsal perfectamente definido.

Del análisis de las mediciones comprobamos que no existe relación directa entre la longitud de la hoja y la del filo dorsal: el filo más largo, de $28,5 \mathrm{~cm}$, corresponde a la hoja de la falcata 45, pero ésta no es la hoja de mayor longitud; la hoja más larga de entre aquellas que presentan filo, la falcata de la sepultura 53 , con $52,5 \mathrm{~cm}$ de hoja, presenta un filo de $28 \mathrm{~cm}$, y el filo más corto, $20 \mathrm{~cm}$, no pertenece a la hoja más corta, la de la sepultura 27, ya que ésta tiene un filo mayor.

Tampoco es posible observar una tendencia hacia la asociación de determinado tipo de empuñadura con la existencia o no de filo dorsal: entre las que lo tienen contamos con tres empuñaduras del tipo A, (sepulturas 11, 15 y 31); dos del tipo B (sepulturas 27 y 53) y tres del tipo C (sepulturas 6, 45 y 72). Entre las que mantienen el dorso plano hay una empuñadura del tipo A (sepultura 4), dos del tipo B (sepulturas 1 y 41), y dos del tipo C (sepulturas 20 y 67).

Incluso entre las falcatas que presentan filo dorsal no existe una generalización en cuanto a la disposición de las acanaladuras a lo largo de la hoja: las de las sepulturas 15 y 27 pertenecen al tipo I, inidentificables por el estado del metal; la de la sepultura 11 es del tipo II, las 
acanaladuras se abren al inicio del filo dorsal, y las de las sepulturas 31,53 y 72 son del tipo III, con acanaladuras paralelas a lo largo de toda la hoja, sin marcar el inicio del filo.

En cuanto a la relación entre el tipo de empuñadura y las acanaladuras de la hoja, con los datos que disponemos sólo podemos concluir que es indiferente, ya que las cuatro empuñaduras tipo A se asocian en dos casos con acanaladuras tipo III, en un caso al tipo II, y en otro al tipo I. Las empuñaduras tipo B se reparten mejor y se asocian en dos casos al tipo III y en otros dos casos al tipo II. En cambio, en cinco piezas con empuñadura tipo C, las acanaladuras corresponden al tipo III, y una única pieza presenta acanaladuras del tipo I. El alto número de empuñaduras incompletas dificulta el análisis de esta asociación.

Para finalizar el estudio de las hojas de las falcatas cabría mencionar la singularidad de 3 de ellas, respecto al clásico perfil de este tipo de arma:

- la falcata de la sepultura 4 presenta la concavidad del filo principal en el tercio superior de la hoja, justo bajo la guarda basal, en lugar de tenerlo hacia la mitad, lo que unido a que el ancho mínimo que presenta en este punto está por encima de la media, con un valor de $4,5 \mathrm{~cm}$, le confiere un aspecto más «tosco» o pesado que las demás.

- la falcata de la sepultura 6 no presenta la curva dorsal típica, sino que se mantiene casi completamente recta desde la empuñadura hasta la punta, con un ángulo axial de $86^{\circ}$, es decir, casi en ángulo recto, como describiremos más abajo al detallar este aspecto de las falcatas.

- la falcata de la sepultura 67 presenta hacia la mitad del dorso una inflexión que da paso a una hoja marcadamente cóncava.

Estas falcatas presentan además otra característica que las hace diferentes: no poseen el tramo recto que desciende de la guarda basal antes de conformar la concavidad del filo principal. Estas diferencias morfológicas, fuera del elegante equilibrio que presentan las demás piezas, nos hacen pensar en que procedan de un centro de producción distinto.

- Ángulo axial.

Este valor define la curvatura de la falcata. Cuanto mayor sea el ángulo más recta será la falcata, lo que ocurre con el arma de la sepultura 6 , que con $86^{\circ}$ se aproxima al ángulo recto, más propio de una espada que de una falcata. Según la relación inversa que existe entre la longitud y el ángulo, al no presentar apenas esta curva, estas falcatas pueden ser más cortas. Aunque la falcata mencionada no está completa, calculamos que no excedería los $41 \mathrm{~cm}$ de longitud de hoja, lo que realmente la convierte en una de las más cortas. En cambio, si el ángulo es elevado el arma presentará dificultades funcionales, puesto que a su corta longitud se unirá una curva pronunciada.

En el otro extremo tenemos el menor ángulo, $58^{\circ}$, en la falcata más larga, la de la sepultura 41, con $58 \mathrm{~cm}$ de hoja. A mayor longitud de hoja, más pronunciada puede ser la curva, esto es, un ángulo menor.

La media que obtenemos es de $73^{\circ}$, con el grupo más numeroso dispuesto entre los $70^{\circ}$ y $77^{\circ}$.

- VAINA

De las 22 sepulturas que cuentan con falcata, 18 conservan los elementos de refuerzo de la vaina, en diferentes grados de conservación y el resto de sepulturas con falcata no los presentan.

También se da el caso contrario: vaina de falcata sin que aparezcan restos del arma. Esto sucede en dos casos, en los que habrá que aceptar que sólo la funda fue incinerada, sin con- 
tener la falcata, por motivos que ignoramos. Tal vez se trate de la representación de la parte por el todo.

Hemos mencionado al principio del capítulo que las sepulturas 15 y 27 aportaban una falcata y restos de otra, sin embargo sólo aparecen restos de una sola vaina.

- Tipología.

Para el estudio de los herrajes de suspensión de vaina hemos seguido la tipología descrita por E. Cuadrado (Cuadrado, 1989: 23).

En esta necrópolis el tipo que aparece en las sepulturas es el compuesto por la embocadura y dos guarniciones, sin refuerzos laterales metálicos.

El tipo de embocadura que predomina es el $1 \mathrm{~b}$ de Cuadrado, con el apéndice correspondiente al dorso ligeramente más alto que el del filo, abierto y asegurado por remaches. Sólo en un caso, el de la sepultura 31, la embocadura pertenece al tipo 1a, con los apéndices de igual altura. La embocadura de la falcata de la sepultura 67 presenta los dos extremos abiertos, por lo que no encaja en ninguno de los tipos descritos.

Las guarniciones para la suspensión que se han conservado lo suficiente para poder atribuirles un tipo determinado, pertenecen en todos los casos al B, con la anchura posterior de la cinta reducida respecto a la parte delantera. En los casos en que el metal permite reconocerlo, presentan el ensanchamiento para contener el cuchillo afalcatado.

En las sepulturas 1 y 53, además de estas guarniciones, aparecen unos refuerzos metálicos, a la vez que elementos ornamentales, que se acoplarían al tercio distal de la vaina, formados por una espiga central, de la que parten unas abrazaderas, dos en la sepultura $1, \mathrm{y}$ tres en la sepultura 53, que a su vez rodeaban la vaina. En el caso de la sepultura 53 este conjunto se remata con un apéndice que protegería el extremo apuntado de la funda (Moltó y Reig, 1996: 128, lám. 7)

Estas piezas se describen con más detalle en el apartado dedicado a las decoraciones, ya que muestran una elaborada decoración.

\section{FALCATAS DECORADAS}

Cinco son las sepulturas que aportan falcatas con decoración damasquinada en plata: la sepultura 1, cuya falcata reveló en una radiografía que había decoración en su hoja, y en el refuerzo de vaina ya mencionado; la sepultura 27 , con la cartela de la falcata decorada; la sepultura 41, la sepultura 53, cuya falcata ha sido recientemente restaurada, así como un refuerzo de vaina igualmente decorado (Moltó y Reig, 1996; Prats i Darder et alii, 1996), y la sepultura 74, con la cartela decorada.

Exceptuando el fragmento aparecido en la sepultura 74, las restantes son piezas con empuñadura de cabeza de caballo y guarda lateral de barra maciza. En cambio no presentan uniformidad en cuanto a la disposición de las acanaladuras bajo el puño o en la hoja, ya que la falcata de la sepultura 27 y la de la sepultura 53 tienen las acanaladuras abiertas en abanico bajo la guarda, la procedente de la sepultura 41 las presenta paralelas, y en la pieza de la sepultura 1 no es posible apreciar su disposición. A lo largo de la hoja, las acanaladuras resultan inidentificables (tipo I) en dos casos, mientras que en los otros son del tipo III.

Tampoco existe uniformidad en otras variantes como las longitudes, ángulos axiales, o presencia/ausencia de filo dorsal.

- Sepultura 1.

Esta falcata presenta una gruesa capa de óxido por lo que no se apreciaban indicios de que pudiera tener decoración, no obstante se le realizó una radiografía que reveló una decoración a base de líneas de dientes de lobo en su hoja, entre las acanaladuras. 


$$
\delta
$$




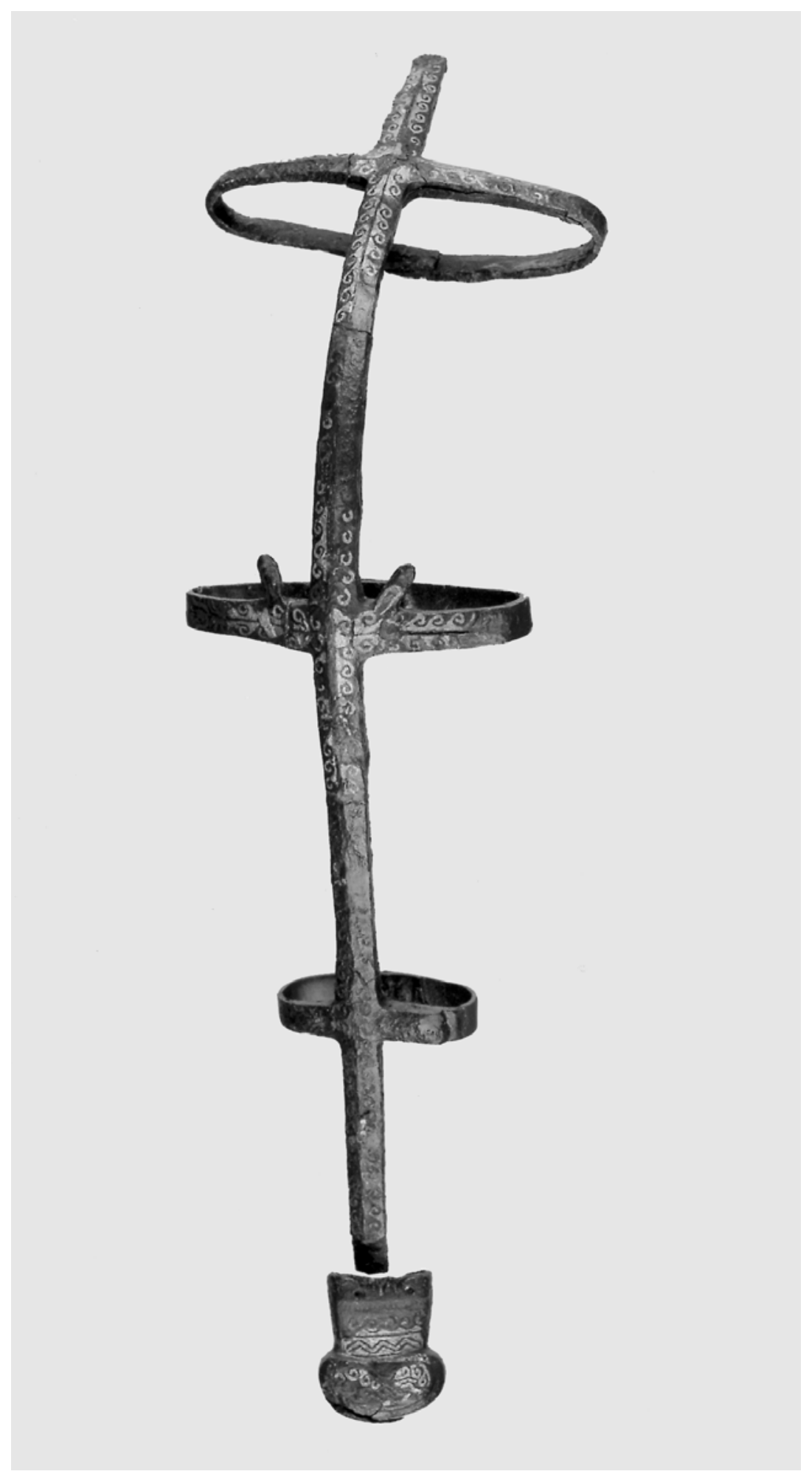

Lám. IV. Refuerzo de vaina/elemento ornamental, decorado con damasquinados, de la falcata procedente de la sep. 53. 
El refuerzo de vaina está formado por una espiga central decorada longitudinalmente por 2 bandas paralelas de espirales enlazadas. De esta espiga parten, a diferente altura, 2 abrazaderas que rodearían la vaina, las cuales adoptan una forma curva en su nacimiento, y que presentan una decoración con un motivo serpentiforme, al extremo del cual se distinguen dos ojos, según se aprecia en la radiografía obtenida de la pieza. La espiga central se remata con un pequeño apéndice redondeado, decorado con incisiones paralelas.

- Sepultura 27.

Esta falcata tiene la cartela y el dorso decorados (lám. II). En la cartela se disponen cuatro bandas horizontales que de arriba abajo presentan espirales enlazadas, doble línea de dientes de lobo, zarcillos enlazados y línea de dientes de lobo. En el dorso aparece una figura invertida, compuesta por un triángulo con la base orientada hacia la empuñadura y en cuyo vértice la prolongación de los laterales se curva hacia afuera. Esta figura se corona con un pequeño triángulo.

- Sepultura 41.

A pesar del mal estado de conservación de esta pieza, es posible descubrir en el dorso, a la altura de la cartela, una serie de dientes de lobo en disposición horizontal, seguida por otra serie compuesta por grandes liras. Bajo estos motivos, aparece de nuevo la figura triangular invertida, con los extremos superiores curvados hacia afuera, esta vez sin ningún tipo de remate.

En el extremo distal de la hoja, donde las acanaladuras se unen, aparecen unas hojas de hiedra de tallos largos, los cuales se prolongan conformando los laterales de un triángulo, en cuyo vértice se distingue una figura triangular.

\section{- Sepultura 53.}

Esta pieza es la que muestra una decoración más compleja, variada y con una mejor calidad técnica (lám. III).

- Empuñadura:

- cartela a: queda enmarcada por una línea de dientes de lobo, con los motivos decorativos dispuestos en bandas horizontales, de arriba abajo, de la siguiente manera: líneas onduladas, espirales enlazadas, hojas de hiedra, dientes de lobo, líneas onduladas, espirales enlazadas, una hoja de palma y zarcillos enlazados.

- cartela b: igualmente enmarcada por una línea de dientes de lobo, y con casi idénticos motivos que la cara anterior, dispuestos de la siguiente forma: líneas verticales, espirales enlazadas, hiedras enlazadas, palmetas de cuenco estilizadas, una hoja de palma, espirales enlazadas y hiedras enlazadas. La base de la guarda basal, en ambas caras, está recorrida en su totalidad por una línea de dientes de lobo y bajo ella una línea de espirales enlazadas. En la zona del interior de la cartela, muesca de base y apéndice de la guarda lateral aparece otra línea de espirales enlazadas.

Si bien ambas caras no son idénticas en cuanto a los temas decorativos y su disposición, sí que comparten la mayoría de ellos, sólo las liras y palmetas las diferencia por aparecer únicamente en una cara.

- dorso de la cartela: está decorado con tres líneas de dientes de lobo dispuestas en vertical, y series horizontales de espirales, zarcillos, dientes de lobo, espirales y 
zarcillos, todo ello enmarcado por dientes de lobo. Bajo este grupo, en el arranque de la hoja, se representa una figura triangular de cuyo vértice parten dos líneas curvas contrapuestas hacia ambos lados. Sobre el vértice de esta figura aparece un círculo inserto en un motivo en $U$ con los extremos superiores abiertos hacia ambos lados. Esta figura está dispuesta en posición invertida (respecto a la orientación de la falcata).

- guarda lateral maciza, de sección circular formada por dos cabezas masculinas unidas por la parte superior de la cabeza, y parte de una tercera que enlaza con el apéndice de la guarda basal. Están siendo devoradas por un animal de aspecto felino que resulta de la prolongación del hocico del caballo (empuñadura). Los detalles de las cabezas y del animal están resaltados mediante los damasquinados en plata. En la zona correspondiente al cuello del felino se repiten los motivos decorativos que aparecen en la cartela: hojas de hiedra, dientes de lobo, espirales enlazadas, etc.

- apéndice de la guarda basal: se aprecia un motivo estrellado. Todo el borde de la guarda basal, incluida cartela, escotadura y apéndice, está decorado con dientes de lobo y espirales enlazadas.

En la hoja, bajo la guarda basal y en paralelo a ella, enmarcando las acanaladuras se dispone una banda compuesta por dos líneas de dientes de lobo que encierran una de espirales enlazadas. En el ángulo formado por la línea paralela y la que recorre la hoja aparece un motivo decorativo que se repetirá a lo largo de toda la hoja por ambas caras: sobre la línea más interna de dientes de lobo se dispone un motivo vegetal en forma de bulbo del que parten pequeñísimas hebras y que identificamos como una granada o flor de adormidera.

En la zona donde el dorso se convierte en filo dorsal, aproximadamente a $28 \mathrm{~cm}$ de la punta, aparece otra figura triangular, con el vértice abierto y prolongado hacia los lados y hacia abajo en líneas curvas. Inscrito en el triángulo que conforma el cuerpo principal se distingue una línea vertical en cuyo extremo superior se abre una U con los extremos levemente curvados hacia afuera, y con un círculo en su interior, sobre el cual se dispone una pequeña línea curva. En la zona cercana a la punta, en ambas caras, donde se juntan las dos series de acanaladuras y las dos bandas decorativas que las enmarcan, se forma una figura triangular en cuyo vértice se disponen dos motivos vegetales, posiblemente de palma, como los que aparecen en la cartela, en posición horizontal, y sobre éstos tres U concéntricas con los extremos abiertos y curvados hacia ambos lados, y en el interior del motivo central, de nuevo un círculo (Moltó y Reig, 1996: 127, lám. 5 y 6).

El refuerzo de vaina, está compuesto por una espiga central decorada con dos bandas de espirales enlazadas que la recorren longitudinalmente. De ésta parten tres abrazaderas decoradas con idéntico motivo, en el extremo de las cuales se repite el diseño que aparece en la hoja de la falcata: el pequeño bulbo con hebras o adormideras. La espiga central se remata con un apéndice en forma arriñonada decorado con dientes de lobo, espirales enlazadas y líneas onduladas (lám. IV).

\section{- Sepultura 74}

En esta sepultura sólo se depositó la cartela de una falcata, con los siguientes motivos decorativos: en una secuencia de 5 bandas horizontales, separadas entre sí por una línea de dientes de lobo, se disponen en primer lugar hojas de hiedra enlazadas, les sigue una serie de liras estilizadas, a continuación se dispone otra serie de hojas de hiedra, espirales enlazadas y unos motivos vegetales dispuestos en horizontal, que identificamos como una espiga. Toda la cartela está rodeada por dientes de lobo y quedan restos de una serie, exterior a éstos, de espirales enlazadas. 
Los motivos decorativos que hemos descrito son comunes en el mundo mediterráneo, de procedencia helénico-itálica, y se repiten en la decoración de armas ibéricas, principalmente falcatas y en ocasiones lanzas. De forma más compleja y barroca aparecen sobre vasos cerámicos, sin duda por la mayor sencillez de realización y la amplitud de la superficie cerámica.

Destaca sin embargo la profusa decoración del arma de la sepultura 53, con motivos que, si bien no resultan ajenos, sí son poco frecuentes, lo que induce a considerar que esta pieza, muy personalizada, pudo ser realizada ex-profeso para ser depositada como ajuar funerario, a juzgar por el carácter simbólico de dichos motivos.

\section{II. a. 2. Puñal de frontón}

Sólo tenemos un arma de este tipo, la que aporta la sepultura 5 (Cortell et alii, 1992: 98, fig. 10-1).

Se trata de un puñal con hoja de perfiles rectos y un haz central de acanaladuras. La lengüeta es plana, bifurcada, pero no la remata ni un frontón ni antenas, sino unos topes planos que rematan, horizontalmente, cada una de las dos ramas. Conserva tres remaches para la sujeción de las cachas. La guarda presenta muescas en los gavilanes y escotadura semicircular inferior. En los laterales, sobre el filo, también se aprecian unas muescas (lám. V).

Es difícil adscribir esta pieza dentro de una tipología puesto que comparte características de los puñales de frontón y de antenas atrofiadas. Si bien la hoja es propia de las armas del primer tipo: triangular, alargada, con la base no muy ancha, y acanaladuras centrales, los topes horizontales que rematan las dos antenas no son propios para añadirles el frontón típico de este tipo.

La diferencia la marca la empuñadura, que reúne las características de las armas pertenecientes al tipo de antenas atrofiadas, variante Alcácer do Sal (Cabré de Morán y Morán Cabré, 1979; Cuadrado, 1963; Vaquerizo, 1990: 226-227). Las empuñaduras de las armas que reciben esta denominación son facetadas, como posiblemente sería la empuñadura de este puñal con el recubrimiento de las cachas, con muescas en los gavilanes y en los laterales sobre el filo, al igual que el arma que estudiamos, y escotadura semicircular en la cruz, otra característica que comparte nuestro puñal.

Mantenemos la clasificación propuesta por F. Quesada que lo adscribe a su tipo I variante B, esto es, como puñal de frontón, (1997: 279, fig. 164-165) aunque opinamos que nos encontramos ante un arma híbrida que comparte características con ejemplares de antenas atrofiadas.

Las dimensiones de la pieza se ajustan a las medias propuestas: $33,5 \mathrm{~cm}$. de longitud total, frente a los 33,8 cm, obtenidos (Quesada, 1997: 276, fig. 160) y $24 \mathrm{~cm}$. de longitud de hoja, algo por encima de los $22,6 \mathrm{~cm}$. propuestos, con lo que se aproxima más al valor máximo fijado en $26 \mathrm{~cm}$. La long. de la empuñadura es de $9,5 \mathrm{~cm}$ con un ancho en la base de $6,2 \mathrm{~cm}$; el ancho máximo de la hoja es de $4,2 \mathrm{~cm}$.

\section{II. a. 3. Espada de frontón}

La sepultura 50 nos ha proporcionado un arma de este tipo (lám. VI).

Se trata de una espada de frontón incompleta en el pomo, de hoja pistiliforme con acanaladuras centrales que siguen el perfil de los bordes. La lengüeta es laminar, de forma romboidal, conserva tres remaches en cada cara y aparece doblada en ángulo recto. La guarda presenta una escotadura semicircular para el ajuste de la embocadura de la vaina. La parte frontal de la guarda muestra un calado rematado por una palmeta estilizada, que se proyectaría por encima de las cachas. 


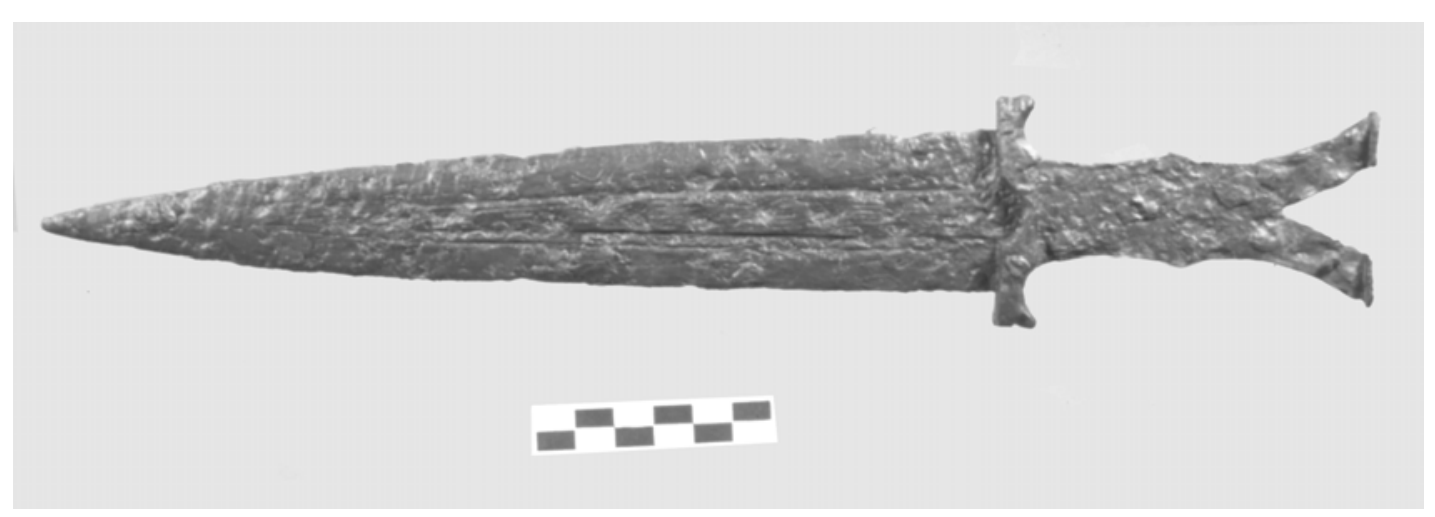

Lám. V. Puñal de frontón. Sepultura 5.

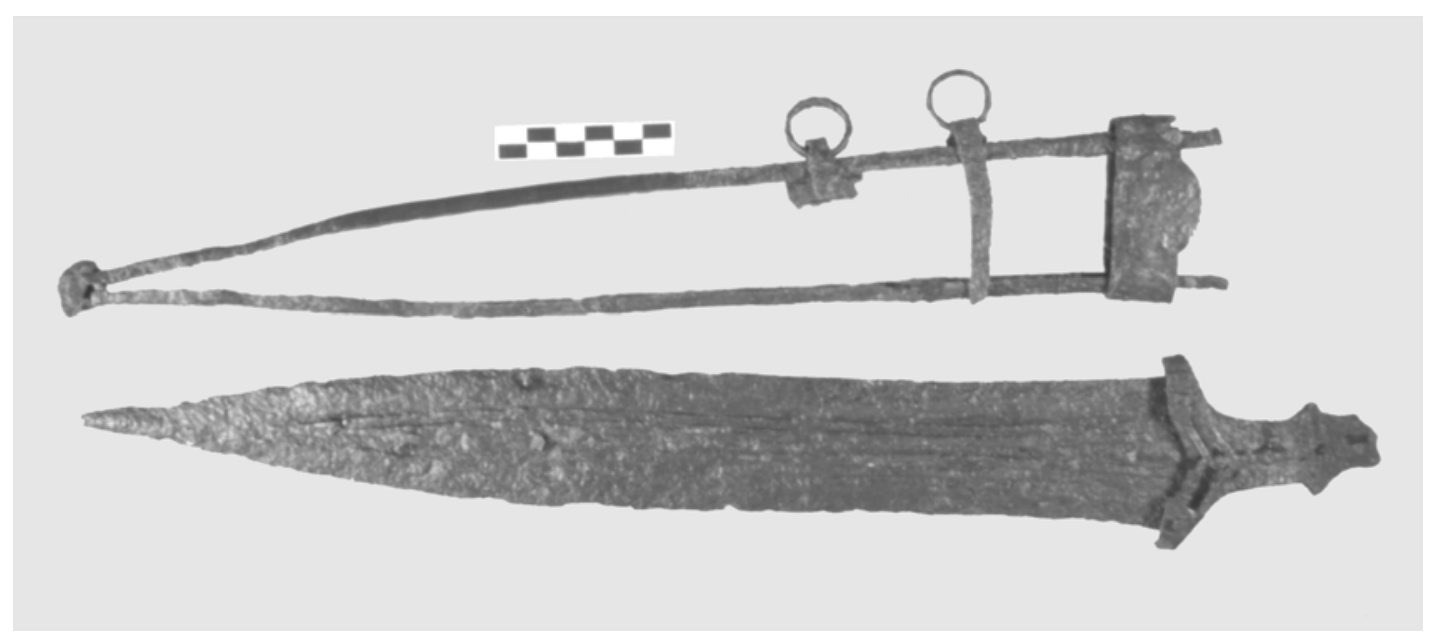

Lám. VI. Espada de frontón y vaina. Sepultura 50.

La vaina se compone de embocadura con apéndice amplio y curvo, que se ajusta a la muesca de la cruz, 2 herrajes de suspensión con una anilla cada uno, cantoneras metálicas y remate, en la punta, de tendencia esférica.

Las dimensiones son: $46 \mathrm{~cm}$ de longitud total, de las cuales $37,5 \mathrm{~cm}$ corresponden a la hoja; ancho máx. hoja: $5 \mathrm{~cm}$; ancho mín.: 4,6 cm; long. conservada empuñadura: 9,5 cm; ancho base empuñadura: $6,5 \mathrm{~cm}$.

Aunque no conserva entera la lengüeta, reúne las características que definen el tipo I de Quesada (1997: 186, fig. 98)

\section{II. b. Armas ofensivas con asta}

\section{II. b. 1. Soliferrea}

Sólo contamos con dos soliferrea completos, aunque muy fragmentados, los que aparecieron en la sepultura 1, enrollados entorno a la urna cineraria. 
Miden aproximadamente $2 \mathrm{~m}$. cada uno, con un diámetro máximo de $2 \mathrm{~cm}$ y un mínimo de $1 \mathrm{~cm}$, dependiendo del punto donde se efectúa la medición. Ello puede deberse tanto al estado alterado del hierro como a la posible existencia de una zona regruesada que sirva de empuñadura. Se distinguen las puntas de ambos, pequeñas, triangulares con aletas, del tipo 2A de Quesada (1997: 315, figs. 179 y 182), y los extremos inferiores apuntados. En cuanto al resto del astil, de sección circular, el estado fragmentario y exfoliado del metal hace difícil su clasificación tipológica entre el tipo A, con zona regruesada para la empuñadura, o el tipo $\mathrm{F}$, con un diámetro constante en toda su longitud.

En la sepultura 20 aparece otro soliferreum, fragmentado, doblado e incompleto. Su longitud conservada alcanza $1,33 \mathrm{~m}$. y el diámetro es de algo más de $1 \mathrm{~cm}$. En este caso no se conserva ni la punta ni el extremo inferior, por lo que es imposible su clasificación. El astil no presenta zonas de empuñadura, sino que mantiene el diámetro casi constante, lo cual le incluiría en el tipo F.

\section{II. b. 2. Pilum}

En la sepultura 1 aparece el único ejemplar completo de pilum: es del tipo II de Quesada (1997: 328): se trata de un pilum cuya punta presenta una leve arista central y sección romboidal. En nuestra pieza el astil presenta sección circular (Cortell et alii, 1992: 100, fig. 12, 7).

La longitud es de $36,5 \mathrm{~cm}$, lo cual lo incluye en la clasificación de pequeños, que comprende armas de entre 20 y $40 \mathrm{~cm}$.

\section{II. b. 3. Indet. Sol/pil}

Incluimos en esta categoría las piezas que nos ofrecen dudas por su estado fragmentado e incompleto. En la sepultura 41 aparece un arma fragmentada en dos partes, la más larga de la cual, con $31,4 \mathrm{~cm}$. presenta el extremo apuntado y una sección circular de algo más de $1 \mathrm{~cm}$ de diámetro. El fragmento corto aparece doblado, con una longitud de $13,1 \mathrm{~cm}$. Podría tratarse de un pilum incompleto, del tipo III y tamaño mediano, o bien ser una pequeña parte de un soliferreum con la punta del tipo 1 , o el extremo apuntado inferior de cualquier tipo de soliferreum.

La sepultura 69 aportó en su ajuar un arma fragmentada en tres partes, con una longitud de $41 \mathrm{~cm}$ para el fragmento mayor. La sección es cuadrada, aunque está muy alterada por las exfoliaciones del hierro, y el diámetro es de $1 \mathrm{~cm}$. No presentan extremos aguzados ni presencia de punta, lo cual significa que los fragmentos son restos del astil de un arma arrojadiza pesada, un soliferreum o un pilum grande, sin que sea posible concretar más.

En la sepultura 70 aparecieron fragmentos de entre 10 y $3,5 \mathrm{~cm}$ de longitud, alguno de ellos doblado. Presentan una sección circular, con un diámetro próximo a los $2 \mathrm{~cm}$. Ninguno de ellos presenta restos de punta, así que simplemente podemos decir que se trata de fragmentos del astil de un arma arrojadiza. Tal vez el mayor diámetro que presentan apunte más a la posibilidad de que se trate de los restos de un soliferreum, pero es sólo un indicio.

\section{II. b. 4. Lanzas}

Son 18 las sepulturas que cuentan con lanzas en su ajuar. El número total de lanzas es de 21, en el que hemos incluido las dos jabalinas, ya que su distinción obedece más a criterios funcionales, estudiados más adelante, que morfológicos, que abordamos ahora.

Como se desprende de los totales hay tres sepulturas en las que aparecen 2 lanzas: sepultura 1,4 y 38 . 
Tal como ya hicimos con la falcata, para el estudio de las lanzas sólo contaremos con las trece piezas enteras que pueden aportar los datos necesarios para su clasificación tipológica y cronológica. El resto de las lanzas presentan distintos grados de conservación que van desde fragmentos de escasos centímetros hasta piezas algo más enteras pero incompletas, por lo que no es posible su estudio tipológico.

Para éste hemos seguido la propuesta que presenta F. Quesada (1997: 357, fig. 207), basada en la combinación de distintas variables: morfología, índice de proporciones y sección de la hoja. La ausencia de determinadas partes de una lanza determina la imposibilidad de verificar alguna de las variables a considerar y por lo tanto no resulta posible una clasificación fiable, si acaso una aproximación o propuesta.

En el cuadro (fig. 4) quedan reflejadas las medidas de cada una de las partes de las lanzas, incluyendo aquellas, marcadas con un asterisco, que aun estando incompletas no impiden su estudio completo. En las columnas siguientes se indica la variante a la que pertenecen y el tipo en el que se incluyen.

\begin{tabular}{|c|c|c|c|c|c|c|c|}
\hline \multicolumn{8}{|c|}{ LANZAS } \\
\hline \multirow{2}{*}{ SEP } & \multicolumn{5}{|c|}{ MEDIDAS } & \multirow{2}{*}{ Variante } & \multirow{2}{*}{ Tipo } \\
\hline & Long. total & Long. hoja & Ancho máx. h. & Long. cubo & Diám. cubo. & & \\
\hline 1 & $36 \mathrm{~cm}$ & $26 \mathrm{~cm}$ & $4,5 \mathrm{~cm}$ & $10 \mathrm{~cm}$ & $2,2 \mathrm{~cm}$ & VB1 & $5 \mathrm{a}$ \\
\hline 1 & $* 21 \mathrm{~cm}$ & $* 13,5 \mathrm{~cm}$ & $2,5 \mathrm{~cm}$ & $7,5 \mathrm{~cm}$ & $2,7 \mathrm{~cm}$ & VB1 & $5 a$ \\
\hline 4 & $45,2 \mathrm{~cm}$ & $32 \mathrm{~cm}$ & $3 \mathrm{~cm}$ & $13,2 \mathrm{~cm}$ & $2,1 \mathrm{~cm}$ & VIA2 & $2 b$ \\
\hline 4 & $* 31 \mathrm{~cm}$ & $* 20 \mathrm{~cm}$ & $2,6 \mathrm{~cm}$ & $11 \mathrm{~cm}$ & $2,2 \mathrm{~cm}$ & VIB2 & $6 a$ \\
\hline 5 & $* 20,5 \mathrm{~cm}$ & $* 12,5 \mathrm{~cm}$ & $4 \mathrm{~cm}$ & $8 \mathrm{~cm}$ & $2,2 \mathrm{~cm}$ & VIC2 & $6 a$ \\
\hline 6 & $* 11,8 \mathrm{~cm}$ & $* 5 \mathrm{~cm}$ & $* 2,3 \mathrm{~cm}$ & $7 \mathrm{~cm}$ & $2,1 \mathrm{~cm}$ & XIC1 & $12 \mathrm{c}$ \\
\hline 11 & $* 16,1 \mathrm{~cm}$ & $* 9,4 \mathrm{~cm}$ & $3,1 \mathrm{~cm}$ & $6,7 \mathrm{~cm}$ & $1,8 \mathrm{~cm}$ & XIC2 & $12 \mathrm{c}$ \\
\hline 23 & & $* 5,1 \mathrm{~cm}$ & $* 2,1 \mathrm{~cm}$ & & & & \\
\hline 27 & $* 14,5 \mathrm{~cm}$ & $* 8 \mathrm{~cm}$ & $* 3,5 \mathrm{~cm}$ & $6,5 \mathrm{~cm}$ & $2,2 \mathrm{~cm}$ & & \\
\hline 29 & & $* 4,9 \mathrm{~cm}$ & $* 2,6 \mathrm{~cm}$ & & & & \\
\hline 31 & $* 21 \mathrm{~cm}$ & $* 15 \mathrm{~cm}$ & $4,2 \mathrm{~cm}$ & $6 \mathrm{~cm}$ & $2,1 \mathrm{~cm}$ & VIC2 & $6 a$ \\
\hline 35 & $51 \mathrm{~cm}$ & $40 \mathrm{~cm}$ & $2,8 \mathrm{~cm}$ & $11 \mathrm{~cm}$ & $2,1 \mathrm{~cm}$ & VIA1 & $2 b$ \\
\hline 38 & & $* 7,5 \mathrm{~cm}$ & $* 2,5 \mathrm{~cm}$ & & & & \\
\hline 38 & & $* 5,3 \mathrm{~cm}$ & $* 2 \mathrm{~cm}$ & & & & \\
\hline 41 & $30 \mathrm{~cm}$ & $22,5 \mathrm{~cm}$ & $4 \mathrm{~cm}$ & $7,5 \mathrm{~cm}$ & $2,3 \mathrm{~cm}$ & VB1 & $5 a$ \\
\hline 45 & $23 \mathrm{~cm}$ & $15 \mathrm{~cm}$ & $4,4 \mathrm{~cm}$ & $8 \mathrm{~cm}$ & $2,4 \mathrm{~cm}$ & $\mathrm{VC} 2$ & $5 a$ \\
\hline 51 & & $* 3,5 \mathrm{~cm}$ & $* 2,5 \mathrm{~cm}$ & $* 5,2 \mathrm{~cm}$ & $2 \mathrm{~cm}$ & & \\
\hline 53 & & $* 15 \mathrm{~cm}$ & $* 3,4 \mathrm{~cm}$ & $* 6,4 \mathrm{~cm}$ & $2,2 \mathrm{~cm}$ & & \\
\hline 67 & $55 \mathrm{~cm}$ & $44 \mathrm{~cm}$ & $3,6 \mathrm{~cm}$ & $11 \mathrm{~cm}$ & $2,5 \mathrm{~cm}$ & VIA1 & $2 b$ \\
\hline 72 & & $* 3,3 \mathrm{~cm}$ & $* 2,3 \mathrm{~cm}$ & & & & \\
\hline 80 & $* 23 \mathrm{~cm}$ & $* 12,5 \mathrm{~cm}$ & $3,5 \mathrm{~cm}$ & $10,5 \mathrm{~cm}$ & $2 \mathrm{~cm}$ & VIA1/VIB1 & $2 \mathrm{~b} / 6 \mathrm{a}$ \\
\hline
\end{tabular}

Fig. 4. Cuadro con las longitudes de cada una de las partes de las lanzas, incluyendo su tipo y variante.

\section{MORFOLOGÍA. VARIANTES Y TIPOS}

A la vista del cuadro podemos concluir que, en lo que respecta a la morfología de la hoja, en la necrópolis de La Serreta abundan los tipos V y VI, es decir, hojas en las que el ancho 
máximo se sitúa en el primer quinto y primer cuarto, respectivamente, de su longitud a partir de la base. El tipo XI define a las dos únicas jabalinas. Predomina el tipo VI, con siete lanzas de hoja algo más estilizada, frente al V con sólo cuatro.

Con respecto a las longitudes encontramos más variedad, dependiendo del resultado obtenido con el índice 1. El resultado es que predominan ligeramente las hojas cortas, con tres piezas correspondientes a las sepulturas 5,31 y 45, más las dos jabalinas de las sepulturas 6 y 11. En el extremo opuesto encontramos las largas hojas, tipo A de las sepulturas 35 (lám. VII), 67, 80 y una de la sepultura 4.

Estudiando la asociación entre ambas variantes, y siempre teniendo presente que el escaso número de piezas nos obliga a tomar los resultados como indicios, vemos que el tipo $\mathrm{V}$ se asocia a lanzas medianas y cortas, mientras que el tipo VI, más «estilizado», adopta cualquier tamaño. En cuatro casos este tipo se asocia a hojas largas, como en los casos de las sepulturas 4, 35, 67 y 80. Naturalmente el tipo XI, correspondiente a jabalinas, sólo se asocia con el C, hojas muy cortas.

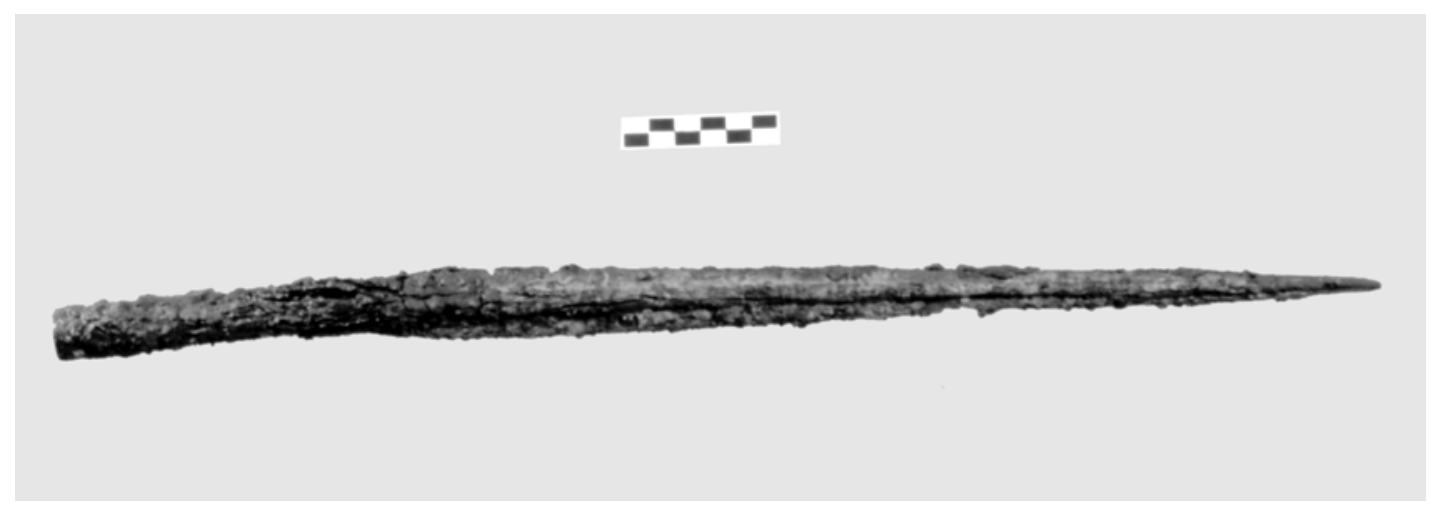

Lám. VII. Lanza tipo 2b, variante VIA1. Sepultura 35.

Respecto a las secciones, encontramos nervios redondeados, tipo 1, y nervios rectangulares, tipo 2. Estos aparecen en cualquier tipo de lanza, indistintamente, sea cual sea el aspecto de la hoja, V, VI o XI, así como en todas las longitudes, sean A, B o C.

Estudiando los tipos en los que quedan incluidas cada una de las variantes obtenidas para cada lanza, resultan:

- tipo 2: corresponde a lanzas grandes, de más de $45 \mathrm{~cm}$, de hoja larga y estrecha, con gran capacidad penetrante, usadas sobre todo empuñadas, ya que su peso impide el ser arrojadas a gran distancia.

- tipos 5 y 6: comprenden la mayoría de las lanzas con que contamos, son de tamaño mediano. Desde el punto de vista funcional se emplearían como armas empuñadas, aunque pudieran ser arrojadas a corta distancia.

- tipo 12: corresponde a las jabalinas, armas arrojadizas.

- Sepulturas con 2 lanzas.

Contamos con tres sepulturas que aportan más de una lanza en su ajuar: la sepultura 1, que cuenta con dos lanzas, dos soliferrea y un pilum, la sepultura 4 con dos lanzas, y la 38 con dos fragmentos de lanzas, correspondientes a la zona de los cubos de enmangue. 
Para abordar la cuestión planteada acerca de las parejas de lanzas y su diferente funcionalidad, empuñadas o arrojadizas, tomando en consideración sus diferentes longitudes, sólo contamos con las dos primeras sepulturas mencionadas, que son las que conservan las lanzas más completas.

Sí existe una diferencia de longitudes entre los pares de lanzas de ambas sepulturas, pero no creemos que en el caso de la sepultura 1 una de ellas sea el arma arrojadiza, puesto que en dicha sepultura ya aparecen armas diseñadas para tal efecto: los dos soliferrea y el pilum, aunque tratándose de lanzas del tipo 5, medianas, evidentemente la más corta de ellas pudiera ser arrojada, sin alcanzar la distancia que se conseguiría con alguna de las específicamente arrojadizas.

En cuanto a la sepultura 4, con un par de lanzas de diferente longitud, hemos de pensar que la mayor corresponde al tipo 2, una lanza demasiado pesada y larga, con $45 \mathrm{~cm}$, para ser arrojada, así que sólo la lanza del tipo 6, de tamaño mediano, pudiera cumplir ocasionalmente esta función, ya que como hemos mencionado más arriba las lanzas pertenecientes a este tipo son, en principio, empuñadas.

\section{LANZAS DECORADAS}

Los trabajos de limpieza que se están efectuando a las armas han revelado la existencia de dos lanzas con decoración damasquinada en plata en el cubo de enmangue; en un caso, sepultura 5, en la zona próxima a la base de la hoja, en el caso de la lanza de la sepultura 11 (Miró y Reig, 1997: 162, lám. 1), se decora la zona cercana a la base del cubo, es decir, en ambas piezas se ha decorado la parte no funcional del arma.

La lanza procedente de la sepultura 5 (lám. VIII), con una cronología de la $1^{\mathrm{a}}$ mitad del s. IV a.C., es una variante VIC, tipo 6, y presenta una decoración de espirales enlazadas, idénticas a las que hemos visto en las falcatas. En el cubo de enmangue se distingue la sutura de cobre que cierra sus extremos (Miró y Reig, 1997), así como las bandas horizontales de plata y cobre, alternadas que, si bien ejercían presión sobre el astil, también resultan un motivo decorativo.

La pieza de la sepultura 11 es una jabalina, variante XIC2, tipo 12c, y presenta una serie de espirales enlazadas en la zona donde aparecen las anillas de presión del cubo.

En ambos casos los motivos decorativos son los habituales en la decoración de falcatas, aunque mucho menos espectaculares, dado el escaso plano disponible para la realización del damasquinado.

Encontramos una circunstancia común a ambas piezas: las dos se asocian a armas de prestigio en sus ajuares. La lanza de la sepultura 5 apareció junto a un puñal, pieza que es considerada como de prestigio en los estudios referentes al armamento ibérico. Y la jabalina se asocia a una panoplia completa, de la cual destaca un umbo de bronce de alto valor simbólico y material que es estudiado en el apartado correspondiente a las armas defensivas, y que se revela como una pieza de gran valor.

\section{REGATONES}

15 sepulturas de las 28 que cuentan con armas en su ajuar presentan regatones. El número total de éstos es de 17, ya que en dos sepulturas aparecen dos ejemplares.

Al realizar el estudio de los tipos de armas hemos dejado aparte la cuestión de las asociaciones para más adelante, centrándonos en la morfología y tipología de las mismas. Sin embargo el estudio de los regatones requiere que nos detengamos en dicho aspecto, su asocia- 


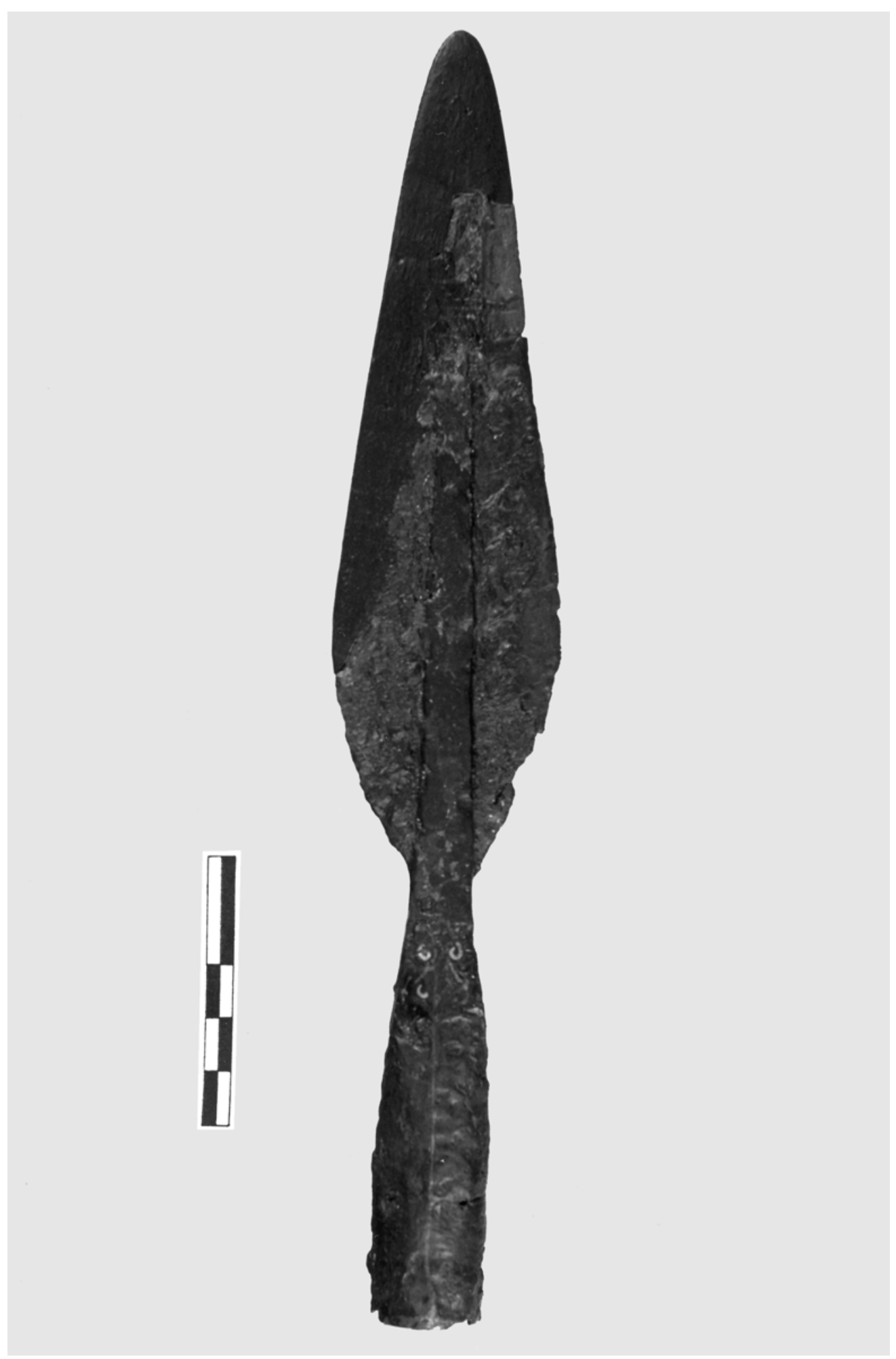

Lám. VIII. Lanza decorada con damasquinados de plata y sutura de cobre que cierra el cubo de enmangue. Sepultura 5. 
ción o no asociación a armas de asta, ya que de la cuestión morfológica hay pocas cosas que decir: son piezas cónicas, que en ocasiones presentan la punta de sección cuadrada, como el que aparece en la sepultura 53; conservan las perforaciones para el pasador del asta, que algunos incluso mantienen; y en algunas piezas es posible ver las acanaladuras que han dejado las anillas de refuerzo en la zona de enmangue, como en el regatón de la sepultura 50; y cuya longitud media es de $10,3 \mathrm{~cm}$, con un mínimo de $8,5 \mathrm{~cm}$ y un máximo de $11 \mathrm{~cm}$, obtenida de los regatones que se han conservado enteros (Miró y Reig, 1997).

Como se desprende del cuadro adjunto (fig. 5), no todas las armas de asta se asocian a regatones, ni siquiera en cantidad, ni todos los regatones se asocian a armas de asta. Es decir, hay lanzas sin regatón, regatones sin lanza, e incluso armas que no deberían asociarse a regatones y lo hacen.

\begin{tabular}{|c|c|c|c|c|c|c|}
\hline \multicolumn{7}{|c|}{ ASOCIACIÓN ARMAS DE ASTA / REGATONES } \\
\hline Sep & Lanza & Jabalina & Pilum & Solif. & Indet. Solif/pil & Regatón \\
\hline 1 & 2 & & 1 & 2 & & 1 \\
\hline 4 & 2 & & & & & 1 \\
\hline 5 & 1 & & & & & \\
\hline 6 & & 1 & & & & 1 \\
\hline 11 & & 1 & & & & 2 \\
\hline 19 & & & & & & 1 \\
\hline 20 & & & & 1 & & 1 \\
\hline 23 & 1 & & & & & \\
\hline 25 & & & & & & 1 \\
\hline 26 & & & & & & 2 \\
\hline 27 & 1 & & & & & \\
\hline 29 & 1 & & & & & 1 \\
\hline 31 & 1 & & & & & \\
\hline 35 & 1 & & & & & 1 \\
\hline 38 & 2 & & & & & \\
\hline 41 & 1 & & & & 1 & \\
\hline 45 & 1 & & & & & \\
\hline 50 & & & & & & 1 \\
\hline 51 & 1 & & & & & \\
\hline 53 & 1 & & & & & 1 \\
\hline 67 & 1 & & & & & \\
\hline 69 & & & & & 1 & 1 \\
\hline 70 & & & & & 1 & 1 \\
\hline 72 & 1 & & & & & 1 \\
\hline 80 & 1 & & & & & \\
\hline SUMA & 19 & 2 & 1 & 3 & 3 & 17 \\
\hline
\end{tabular}

Fig. 5. Cuadro con la asociación de los regatones a las armas de asta.

\section{- Lanza/regatón}

La asociación lanza/regatón se da en escasas sepulturas: las sepulturas 29, 35, 53 y 72, de las cuales sólo la lanza de la sepultura 35 se ha conservado entera y ha permitido su estudio: 
se trata de una lanza tipo $2 b$, larga, pesada, pensada para ser empuñada, y en consecuencia, rematada por un regatón.

\section{- Arma arrojadiza/regatón}

La sepultura 6 también asocia una lanza con un regatón, sin embargo se trata de una jabalina, tipo 12, un arma arrojadiza que, en principio no debería llevarlo.

Las sepulturas 20, 69 y 70 también presentan un arma arrojadiza, soliferreum en el primer caso, e indet. solif/pil en los dos últimos, asociada a un regatón. En el caso de la sepultura 20, al tratarse de un soliferreum, evidentemente el regatón no le pertenece y hay que pensar en una lanza que no figura entre el ajuar. Respecto a las otras dos sepulturas ya hemos indicado más arriba, al estudiar esta categoría de armas, que no es posible conocer a qué arma corresponden los fragmentos conservados, pero sean pilum o soliferreum, tampoco se les asocia un regatón. Nuevamente parece que falte una lanza en dichos ajuares.

La sepultura 11 cuenta sólo con una jabalina, y en cambio aparecen 2 regatones. Aún admitiendo que uno de ellos se asocie a dicha arma, que no lo necesita por tratarse de un arma arrojadiza, queda un regatón sin su correspondiente lanza.

\section{- Regatones sin lanza}

Tampoco aparecen lanzas en las sepulturas 19, 25, 26 y 50, y sin embargo están presentes los regatones.

Se han propuesto algunas teorías para tratar de explicar la presencia de regatones sin su correspondiente lanza: lanzas hincadas, con la punta hacia arriba, con lo que sólo quedaría el regatón; lanzas tan mal conservadas que no han sido identificadas como tales; que los regatones fueran en realidad «lanzas toscas, baratas», es decir, armas de circunstancias, o que, simplemente, algunas lanzas no se enterraran porque no formaban parte del ajuar, no fueron quemadas en la pira por motivos ¿económicos? ¿tal vez no compensaba desprenderse de un arma relativamente cara y se depositó parte de ella? la parte más fácilmente sustituible, la más económica.

Conocemos de cerca la necrópolis de La Serreta y su proceso de excavación y hemos de descartar la primera hipótesis ya que los regatones no aparecen hincados, como sería el caso; solamente en la sepultura 41 se da la circunstancia de una lanza hincada, pero es la hoja la parte clavada a la tierra, sepultura que, por cierto, no conservaba ningún regatón.

Por otra parte, es cierto que el hierro ha llegado hasta nosotros en estado muy alterado: oxidado, exfoliado, fragmentado, piezas incompletas...pero se han podido reconocer como lanzas fragmentos de escasos centímetros.

Queda por tanto la hipótesis que apunta a los regatones como armas de circunstancias, «lanzas baratas» que podría justificarse en algunas sepulturas «pobres» respecto al armamento, tomando con prudencia este término ya que la inclusión de armas en el ajuar, del tipo que sean, ya descarta esta calificación. Sin embargo tenemos el caso de la sepultura 50, con una espada de frontón en el ajuar, que evidencia un alto nivel social/económico difícilmente asimilable a un ajuar pobre.

Hemos de concluir que, analizando cada una de las hipótesis y trasladándolas a la necrópolis de La Serreta y a cada sepultura por separado, se nos escapan los motivos por los que frecuentemente falta la punta de la lanza.

- Lanzas sin regatón

Las sepulturas 1 y 4 presentan dos lanzas cada una, y sin embargo sólo aparece un regatón en al ajuar. Falta uno de éstos en cada sepultura. 
Las sepulturas 5, 23, 27, 31, 38, 41, 45, 51 y 67 tienen lanzas pero no presentan regatones. Esta ausencia es más fácil de justificar que la anterior, más fácilmente asimilable desde el punto de vista funcional: una lanza sigue siendo tal aunque no cuente con regatón.

II. c. Armas defensivas

\section{II. c. 1. A. D. Empuñadas: manillas de escudo}

Las características formales de las manillas de escudo, hechas con una delgada chapa de hierro de perfil irregular y con orificios, hacen de ellas un elemento muy frágil, y de difícil conservación. En ocasiones todo lo que resta de una manilla de escudo son escasos centímetros de asidero o aleta. No obstante estamos seguros de haber identificado todas las manillas de escudo, en diferentes grados de conservación, aparecidas hasta ahora en la necrópolis.

Representan un total de 12, todas ellas pertenecientes al Grupo III de Quesada (1997: 502-506, figs. 290-291), aunque debido a la fragmentación que presentan algunas ha sido imposible afinar más en su tipología: son manillas de aletas triangulares, con sistema de suspensión de gusanillo, es decir, la empuñadura habitual y más extendida del mundo ibérico desde el siglo IV a.C.

Dentro de la homogeneidad estructural del grupo, se advierten diferencias de tamaño y por tanto en el número de elementos de sujeción, además de los elementos de suspensión (1 ó 2 gusanillos por cada aleta), que son los datos que aportan diferencias tipológicas y cronológicas.

En el cuadro (fig. 6) quedan reflejados todos los datos referentes a medidas, con el asterisco añadido a aquellas longitudes incompletas, así como los tipos atribuidos.

No se incluye los restos de la empuñadura de la sepultura 72 porque debido a la mala conservación que presenta ha sido imposible obtener más datos de ella que la sola identificación.

Para profundizar en el estudio de este tipo de piezas nos hemos centrado en las mejor conservadas, las procedentes de las sepulturas 1, 6, 11, 27, 29, 31 y 53.

\begin{tabular}{|c|c|c|c|c|c|}
\hline \multicolumn{7}{|c|}{ MANILLAS DE ESCUDO } & \multirow{2}{*}{ TIPO } \\
\hline \multirow{2}{*}{ SEP. } & \multicolumn{5}{|c|}{ MEDIDAS } \\
\cline { 2 - 5 } & Long. total & Long. aletas & Ancho base & Long. asidero & \\
\hline 1 & $66 \mathrm{~cm}$ & $28,3 \mathrm{~cm}$ & $8,7 \mathrm{~cm}$ & $* 9,5 \mathrm{~cm}$ & IIIB3b \\
\hline 4 & $* 15 \mathrm{~cm}$ & $*$ & $* 5 \mathrm{~cm}$ & $9 \mathrm{~cm}$ & indet. \\
\hline 6 & $* 24,5 \mathrm{~cm}$ & $9,5 \mathrm{~cm}$ & $* 4,5 \mathrm{~cm}$ & $10 \mathrm{~cm}$ & IIIA2 \\
\hline 11 & $* 31 \mathrm{~cm}$ & $* 10,5 \mathrm{~cm}$ & $6,1 \mathrm{~cm}$ & $10,5 \mathrm{~cm}$ & IIIA1 \\
\hline 20 & $* 15,5 \mathrm{~cm}$ & $*$ & $5,6 \mathrm{~cm}$ & $10,5 \mathrm{~cm}$ & indet. \\
\hline 26 & $* 6,8 \mathrm{~cm}$ & $* 6,8 \mathrm{~cm}$ & $*$ & $*$ & indet. \\
\hline 27 & $37 \mathrm{~cm}$ & $14 \mathrm{~cm}$ & $5,5 \mathrm{~cm}$ & $9 \mathrm{~cm}$ & IIIA3 \\
\hline 29 & $37 \mathrm{~cm}$ & $14 \mathrm{~cm}$ & $5,5 \mathrm{~cm}$ & $9 \mathrm{~cm}$ & IIIA3 \\
\hline 31 & $* 19,3 \mathrm{~cm}$ & $9 \mathrm{~cm}$ & $* 4,6 \mathrm{~cm}$ & $9 \mathrm{~cm}$ & IIIA2 \\
\hline 45 & $* 6 \mathrm{~cm}$ & $* 6 \mathrm{~cm}$ & $*$ & $*$ & indet. \\
\hline 53 & $66,4 \mathrm{~cm}$ & $28,5 \mathrm{~cm}$ & $8,6 \mathrm{~cm}$ & $9,5 \mathrm{~cm}$ & IIIB3b \\
\hline
\end{tabular}

Fig. 6. Cuadro con las longitudes de cada una de las partes de las empuñaduras de escudos, incluyendo su tipo. 


\section{TAMAÑOS}

Lo primero que destaca es la diferencia de tamaños, que definen dos grupos: las empuñaduras de las sepulturas 1 y 53, tipo IIIB3b (con 3 ó 4 puntos de sujeción, apéndices en forma de espiral en las aletas y doble sistema de gusanillo), y las restantes, del tipo IIIA con diferentes variantes ( 2 puntos de sujeción y un gusanillo, con y sin apéndices en las aletas).

Las primeras miden $66 \mathrm{~cm}$, que además es el diámetro real del escudo ya que ambas presentan los extremos de las aletas doblados hacia afuera, sobre la parte exterior del escudo (Cortell et alii, 1992: 97, fig. 13.1; Moltó y Reig, 1997: 129, fig. 4.1; Quesada, 1997: 530), hecho que interpretamos como un refuerzo en el sistema de sujeción de la manilla al cuerpo

Las longitudes de las demás oscilan entre los $29 \mathrm{~cm}$ aproximados que tendría la empuñadura de la sep 6 y los $37 \mathrm{~cm}$ que presentan las de las sepulturas 27 y 29 .

\section{PERFILES}

Entre las empuñaduras mejor conservadas predomina el perfil recto, es decir, pertenecían a un escudo plano, que es el habitual en el armamento ibérico, así aparecen las manillas de las sepulturas 1, aunque ligeramente doblada y retorcida, 11, 29, 31 y 53. La de la sepultura 27 está doblada sobre sí misma de forma que nos hace pensar en una inutilización, pero el perfil sigue siendo recto.

Sólo la empuñadura de la sepultura 6 ofrece un perfil claramente cóncavo, con lo que se concluye que correspondía a un escudo cóncavo en su parte exterior (Cortell et alii, 1992: 103, fig. 13.3; Quesada 1997: 528)

De esto se desprende que los escudos representados en los ajuares de la necrópolis de la Serreta eran mayoritariamente planos, pero que se conocía y usaba la variante cóncava.

\section{REPARACIONES}

Hemos apreciado posibles reparaciones en tres manillas: dos que afectan al sistema de sujeción de ésta al cuerpo del escudo, ya que aparecen remaches en diferente posición en cada aleta, incluso morfológicamente distintos, y un posible tercer caso referido al gusanillo.

Los dos primeros casos son las manillas de las sepulturas 1 y 53: en la primera, con cuatro remaches de sujeción por cada aleta, uno en el vértice y tres formando triángulo en la parte media de la misma, aparece uno de más en uno de los extremos inferiores de una de las aletas.

En la manilla de la sepultura 53, con tres elementos de sujeción por aleta, dispuestos uno en el extremo y dos sobre los suplementos laterales en la zona inferior, conserva en una de las aletas un remache más, de cabeza semiesférica, y por tanto distinto a los restantes, situado en uno de los gusanillos. No podemos afirmar si reforzaba a éste o suplía la pérdida del remache del vértice de la aleta, no conservado (Quesada, 1997: 531; Moltó y Reig, 1996: 129).

Respecto al tercer caso, encontramos que el gusanillo de cada una de las aletas de la manilla procedente de la sepultura 27 atraviesa una chapa cuadrada de bronce, lo que para Cuadrado se trata de elementos decorativos que definen su tipo 4 (Cuadrado, 1989: 103, fig. 41), y para Quesada se trata de reparaciones o refuerzos del gusanillo (Quesada, 1997: 531).

\section{II. c. 2. Umbo}

La sepultura 11 presenta una estructura rectangular de piedras dispuesta en sentido SWNE. Esta estructura está superpuesta al conjunto de armas que aparece en el ajuar, y que es- 
tán colocadas siguiendo el eje SW-NE que adopta la estructura. Entre las armas se encuentra una empuñadura de escudo, del tipo IIIA1 de Quesada, colocada en perpendicular sobre la hoja de la falcata. En el centro exacto de dicha estructura se sitúa un umbo de escudo, en bronce, que cubre los restos de la cremación (lám. IX).

Se trata de una pieza de $24,5 \mathrm{~cm}$ de diámetro, hecha sobre una delgada lámina de bronce, con un casquete de $11 \mathrm{~cm}$ de diámetro y una altura de $4 \mathrm{~cm}$ (láms. X y XI), (Cortell et alii, 1992: 103, fig. 14; Prats, 1993). Presenta un orificio en la parte superior del casquete y un leve rehundimiento circular que debe corresponder a un aplique que serviría para su sujeción. La zona plana que rodea éste se encuentra decorada con tres bandas concéntricas, las dos exteriores formadas por pequeñas aspas y la central forma una serie de triángulos unidos por parejas por el vértice, dispuestos sin que lleguen a unirse las parejas en su base. La técnica empleada para la realización de esta decoración es la incisión. Todo el borde del umbo presenta un calado de palmetas, flores de loto y dobles espirales enlazadas anudadas, silueteadas así mismo por una línea incisa. El ancho de esta banda calada es de $3 \mathrm{~cm}$.

Del análisis de la decoración se desprende que se trata de motivos decorativos habituales y que, en diversos grados de estilización ya hemos visto decorando otras armas, como las falcatas o las lanzas.

Quesada lo considera una variante tardía de los grandes tachones de bronce del s. V a.C., que data desde el último tercio del s. VI o principios del V a.C. siendo la pieza de Serreta el ejemplar más tardío de este Grupo I, tipo IC, asignándole una variante sin paralelos, por lo que la considera de producción propia (1997: 509-511, fig. 29,5).

Queda por resolver la cuestión de si dicho umbo corresponde al escudo al cual pertenece la empuñadura, si el umbo es un elemento ornamental que nunca estuvo montado sobre el cuerpo de un escudo, incluso que fuera elaborado especialmente para destinarla al ámbito funerario, o si estamos ante dos escudos diferentes, en cuyo caso faltaría una manilla.

En una ocasión anterior apuntábamos la posibilidad de que se tratara de dos piezas distintas, dos partes de dos escudos (Cortell et alii, 1992) ya que:

- superponiendo umbo y empuñadura observamos que los remaches de ésta quedan a la altura de la zona plana del umbo. En cambio el sistema de suspensión, el gusanillo, queda fuera del diámetro de la pieza de bronce;

- la distancia entre los remaches de sujeción al cuerpo del escudo que presenta la manilla es de $14 \mathrm{~cm}$, lo cual impediría que éstos atravesaran el umbo a la altura de los calados, único lugar que podrían atravesar, ya que el umbo no presenta otro orificio que el superior del casquete;

- cuando se excavó el umbo no se apreciaron restos de óxido o rozaduras que indicaran que la parte interior de éste hubiera estado en contacto con remaches de hierro de la empuñadura;

por todo lo expuesto parece que se trate de dos piezas que nunca formaron parte del mismo escudo, pero al estudiar la estructura y material que conformarían estas armas defensivas, vimos que no había impedimento para que ambos pertenecieran al mismo, ya que se acepta un escudo con cuerpo de madera, recubierto de piel, tal como Quesada menciona «...sería imprescindible que el exterior del escudo se cubriera con cuero o fieltro para crear un forro exterior algo acolchado o flexible que amortiguara los golpes recibidos por el alma de madera, de modo que ésta no se rajara o astillara...».(1997: 492, fig. 286).

Proponemos la siguiente reconstrucción: los remaches de la empuñadura atravesarían, efectivamente el cuerpo de madera, y sobre ellos, cubriéndolos, se dispondría la mencionada capa de piel. Sobre ella, y sujeto por el orificio del casquete a la parte cóncava de madera del escudo (el hueco para la mano), el umbo. Así no hay contacto entre el bronce del umbo y el 


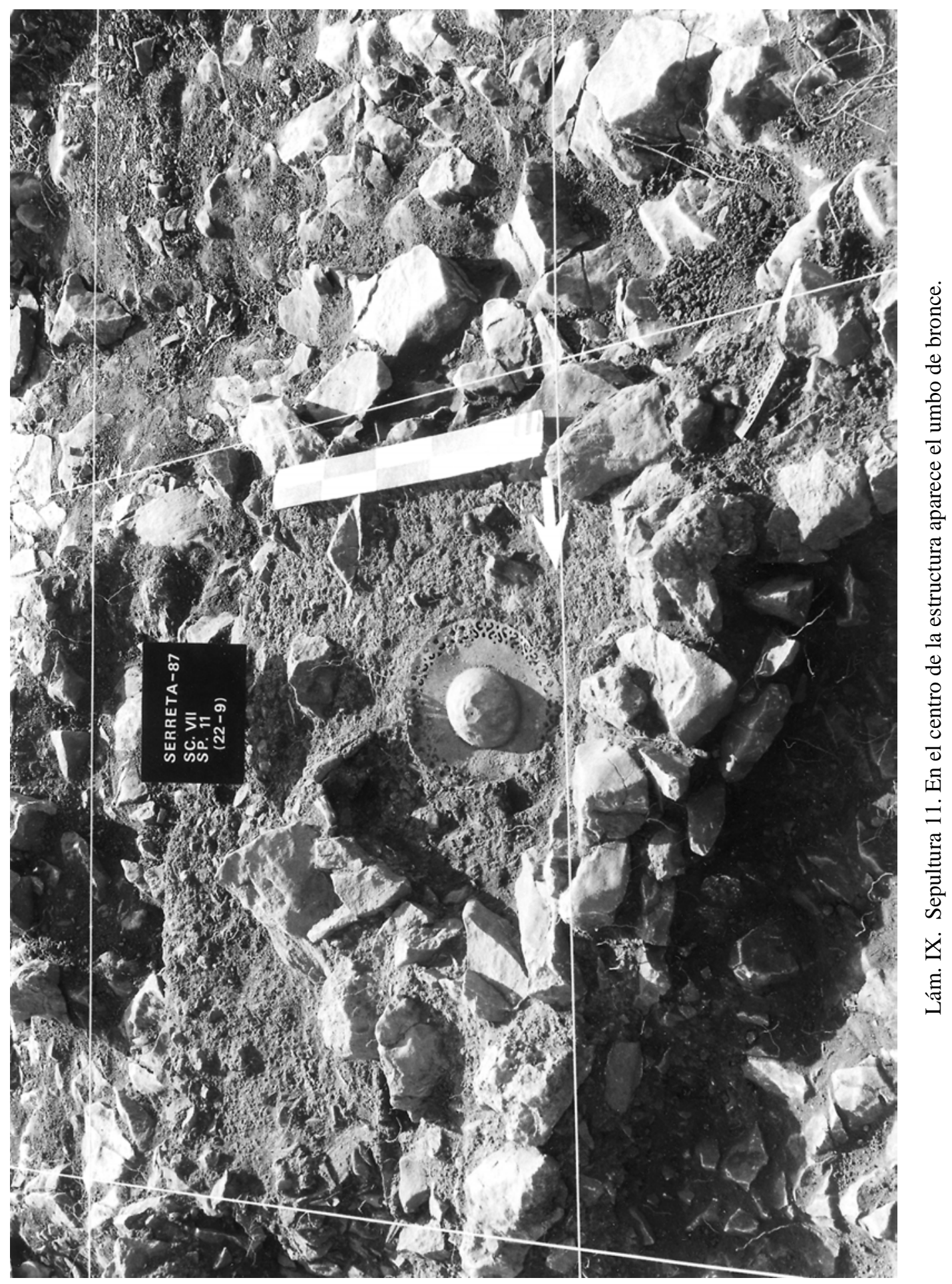




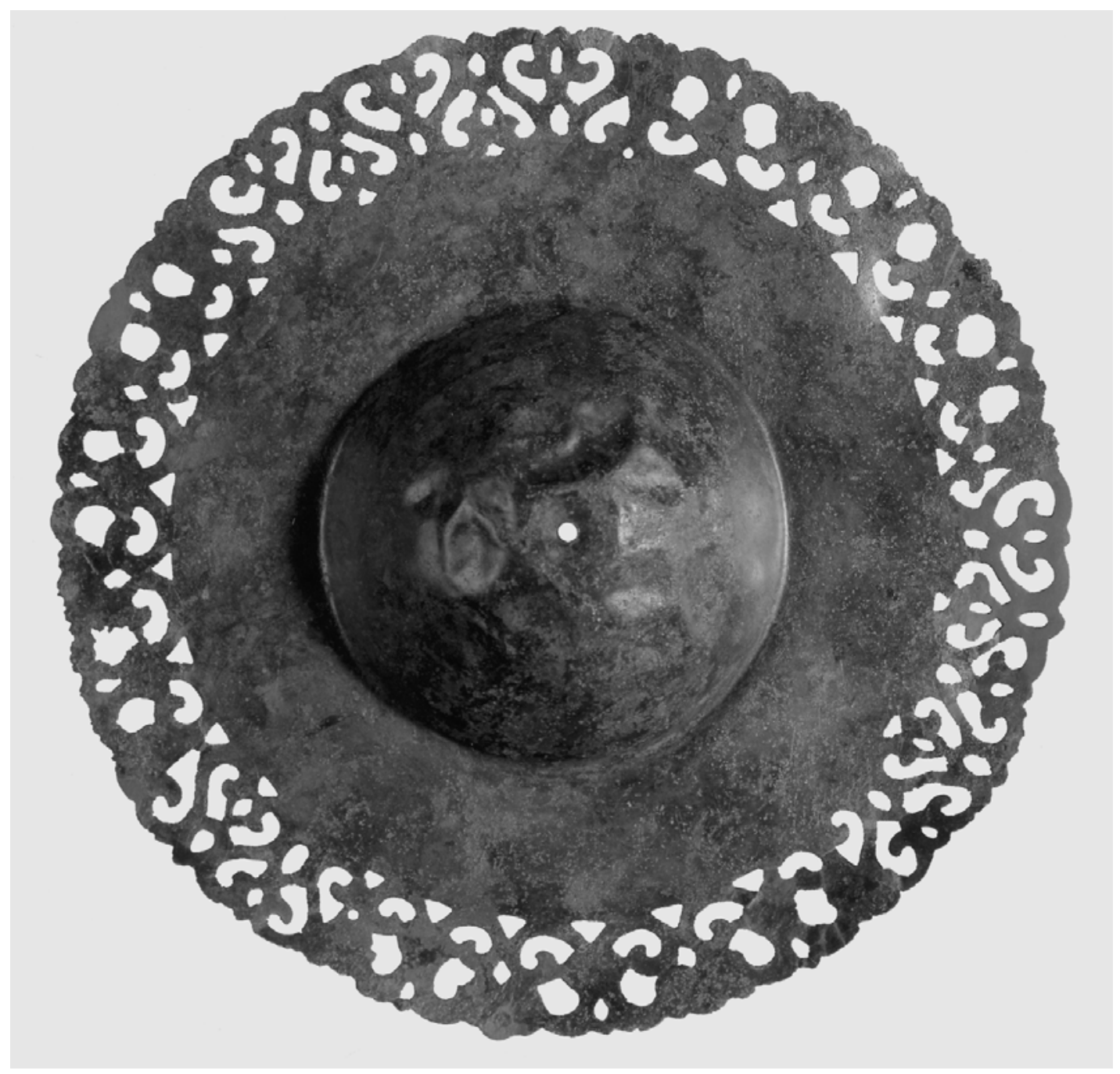

Lám. X. Umbo de bronce. Sepultura 11.

hierro de los remaches. En cambio el sistema de suspensión de gusanillo sí podía atravesar madera y piel (ya hemos mencionado que la longitud entre ambos supera el diámetro del umbo) ya que la holgura del puente es de algo más de $2 \mathrm{~cm}$, contra $1 \mathrm{~cm}$. que presentan los remaches conservados in situ. Las perforaciones que ofrece el calado podían aprovecharse para coser por 3 o 4 puntos el borde del umbo a la piel, y así asegurar el umbo al cuerpo del escudo.

De esta forma ni remaches ni gusanillo atravesarían el bronce y el umbo podría quedar como una pieza individual con sólo desprenderla por un lugar que no causaría su deterioro: el enganche superior del casquete.

Mencionamos este tema porque el umbo no fue quemado en la pira funeraria: la delgada lámina de bronce sobre la que está construido no hubiera resistido la acción directa del fuego sin mostrar mayor deterioro. Sin embargo la empuñadura sí muestra los efectos del calor, por lo tanto creemos que el umbo fue soltado del escudo antes de la cremación, dejándose aparte para su posterior deposición como elemento protector de los restos óseos, como la parte más «noble» de toda la pieza defensiva. 


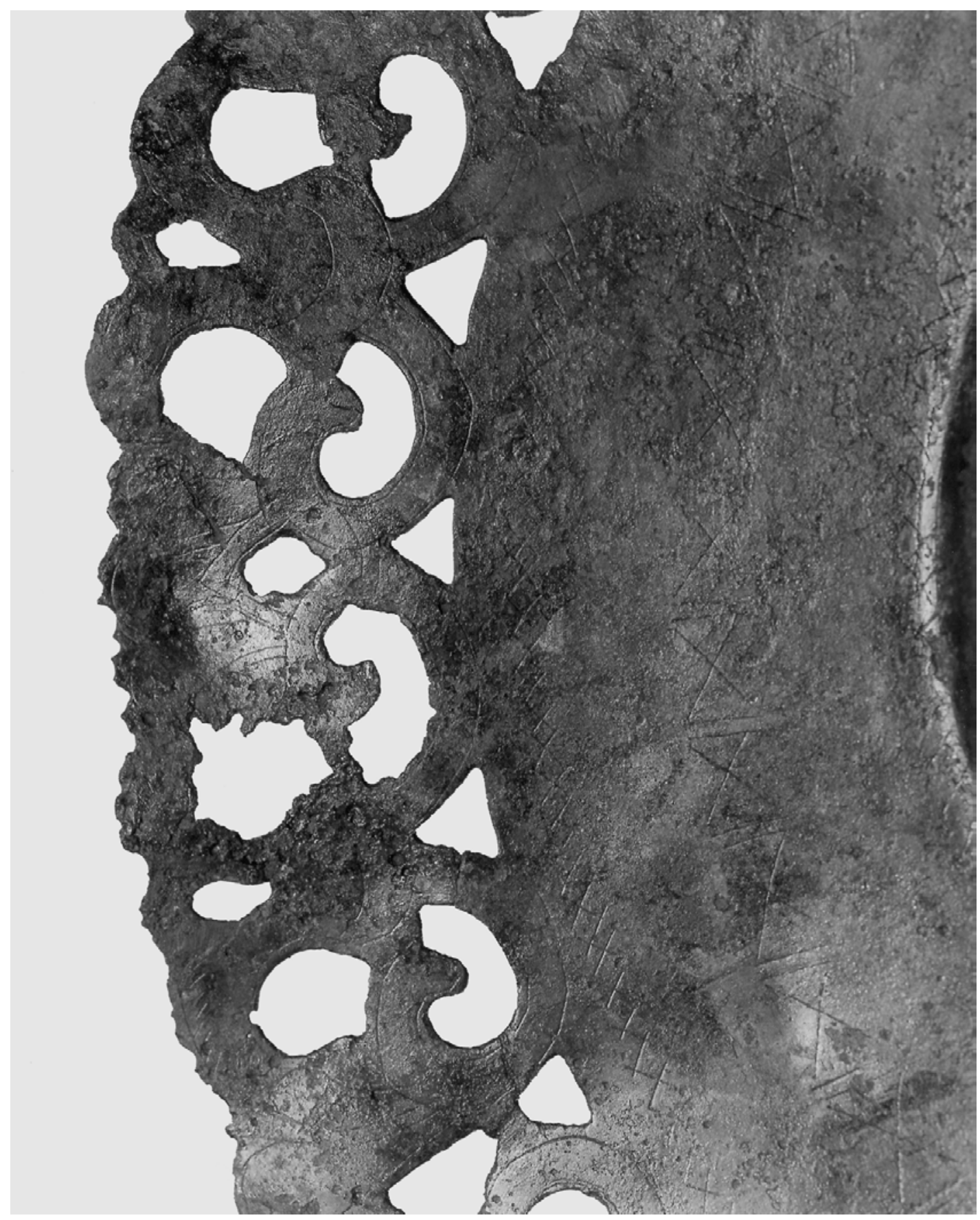

Lám. XI. Detalle de la decoración del umbo de bronce. Sepultura 11. 
Con el resto del escudo se procedió como con el resto de las armas: fueron quemadas. Una vez consumida la parte orgánica del cuerpo, la empuñadura fue a parar al lado de las restantes.

Una vez depositadas las armas se procedió a la construcción de la estructura de piedras -que en parte descansa sobre ellas-, en el interior de la cual se dejan los restos de la cremación del cadáver y sobre éstos, centrado en dicha estructura y cubriendo las cenizas, el umbo.

Cuestión aparte es si este escudo con este umbo fue empleado alguna vez en combate o si se trata de un arma de parada. En la publicación arriba citada ya se menciona que no se observan huellas de golpes producidas por armas, ni cortantes ni aplastantes, y que la perforación cenital no presenta desgaste. La única deformación aparente es el leve abombamiento producido por el propio peso de la cubierta de la sepultura.

En conclusión, no vemos razón para suponer que estamos ante dos piezas, sino que nada impide que ambas sean dos partes de un mismo escudo, cada una de las cuales fue sometida a un ritual distinto: el escudo como arma fue quemado en la pira con las restantes, y el umbo, la parte más noble, más protectora y evidentemente, la de mayor valor, cubrió las cenizas, prolongando en el ámbito funerario su papel en el mundo de los vivos y de la guerra.

\section{II. c. 3. A. D. Corporales: discos - coraza}

Este tipo de protección corporal aparece en el ajuar de la sepultura 4 (Cortell et alii 1992: 103, fig. 15; Quesada, 1997: 572, fig. 325): formado por dos discos de bronce, lisos, con un reborde exterior de hierro. En 4 puntos del reborde exterior, el hierro conforma una abrazadera que sostiene una anilla, por las que probablemente pasaría el correaje o las cadenillas de suspensión. El mejor conservado cubría los restos óseos de la incineración. El otro aparecía inutilizado, doblado sobre sí mismo y retorcido. El diámetro de estos discos es de $25 \mathrm{~cm}$ y el grosor de la lámina de $0,2 \mathrm{~cm}$.

Junto con ellos aparecieron fragmentos de lámina de bronce cuadrangulares, con incisiones en el borde, una de ellas presenta dos cintas estrechas que, dobladas por la mitad y remachadas por vástagos de hierro cerca del borde de la lámina, conforman dos pasadores que, posiblemente, formarían parte de los discos coraza como elementos decorativos del sistema de unión. En el resto del ajuar no se ha detectado la presencia de cadenillas o fragmentos de éstas, que se consideran, junto a las correas de cuero, uno de los dos tipos de elementos de unión de las piezas delantera y trasera.

\section{II. d. Elementos de jinete}

Solo dos sepulturas han aportado en su ajuar piezas relacionadas con el caballo: la sepultura 1, en la que aparecieron dos espuelas, y la sepultura 53, en la que además de las espuelas aparecieron fragmentos de un bocado de caballo.

\section{II. d. 1. Espuelas}

El par de la sepultura 1 (Cortell et alii, 1992: 97, fig. 10.2) apareció dentro de la urna cineraria, mezclado con los restos óseos y otros pequeños elementos del ajuar: se trata de dos grandes espuelas, bien conservadas, formadas por un cuerpo de bronce con los bordes engrosados y un puente rectangular en cada extremo para la sujeción de la correa que aseguraría las espuelas al talón. Tienen una gran aguja de hierro, con la base, moldurada, de bronce. Son asimétricas, es decir, la aguja está descentrada en el cuerpo de bronce, inclinada hacia el interior, de tal forma que cada una de ellas corresponde a un pie determinado (lám. XII). 


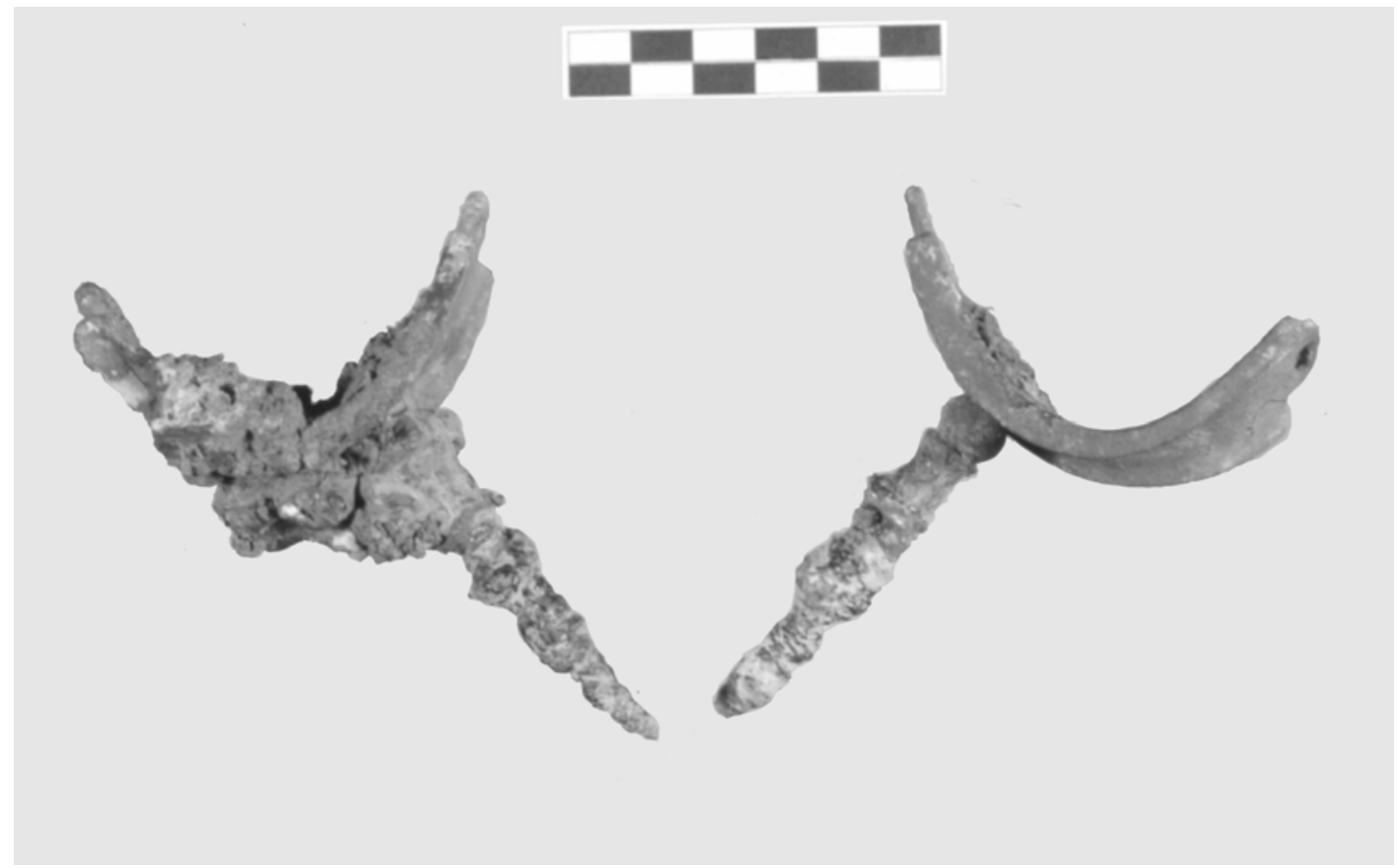

Lám. XII. Espuelas de bronce y hierro, procedentes de la sepultura 1.

También dentro de la urna apareció una pequeña hebilla de bronce, relacionada con la correa de sujeción de una de las espuelas.

El par procedente de la sepultura 53 (Moltó y Reig, 1996: 129, fig. 4.6) está muy mal conservado, ya que además de fragmentadas, las espuelas aparecen incompletas y muy alteradas por la cremación, que las ha soldado entre sí. Se distingue que el cuerpo es de bronce, con una ranura en los extremos, por donde pasaría la correa de sujeción, más una pequeña perforación a cada lado de esta ranura. La aguja, que no se conserva, ha dejado una huella de óxido de hierro soldada a uno de los fragmentos, por lo que suponemos sería de este material, como en el caso de las espuelas de la sepultura 1. Aunque no están completas, sus proporciones nos indican que serían algo menores que las vistas anteriormente.

\section{II. d. 2. Bocado de caballo}

Asociado al par de espuelas aparecidas en la sepultura 53, se presenta un par de anillas grandes, fragmentadas y otras piezas incompletas que identificamos como un bocado de caballo fragmentado e incompleto, si bien nos ha sido posible comparar algunos de los fragmentos con las piezas enteras aparecidas en las sepulturas 277 y 301 del Cigarralejo (Cuadrado, 1987: 475, fig. 203; 513, fig. 222).

Se conserva una anilla casi entera, de unos $8 \mathrm{~cm}$ de diámetro y parte de otra algo menor, así como uno de los grandes eslabones que aún conserva parte de una anilla soldada a él. Un fragmento de hierro con un engrosamiento en el borde podría ser el remate de una de las piezas curvas. No se han conservado más fragmentos que resulten identificables, por lo que estamos convencidos que el bocado no se depositó entero en la sepultura.

A pesar de su estado incompleto y fragmentado se depositó entre el ajuar de forma cuidadosa: centrado entre los dos fragmentos de la falcata y el escudo, que lo rodeaban. 


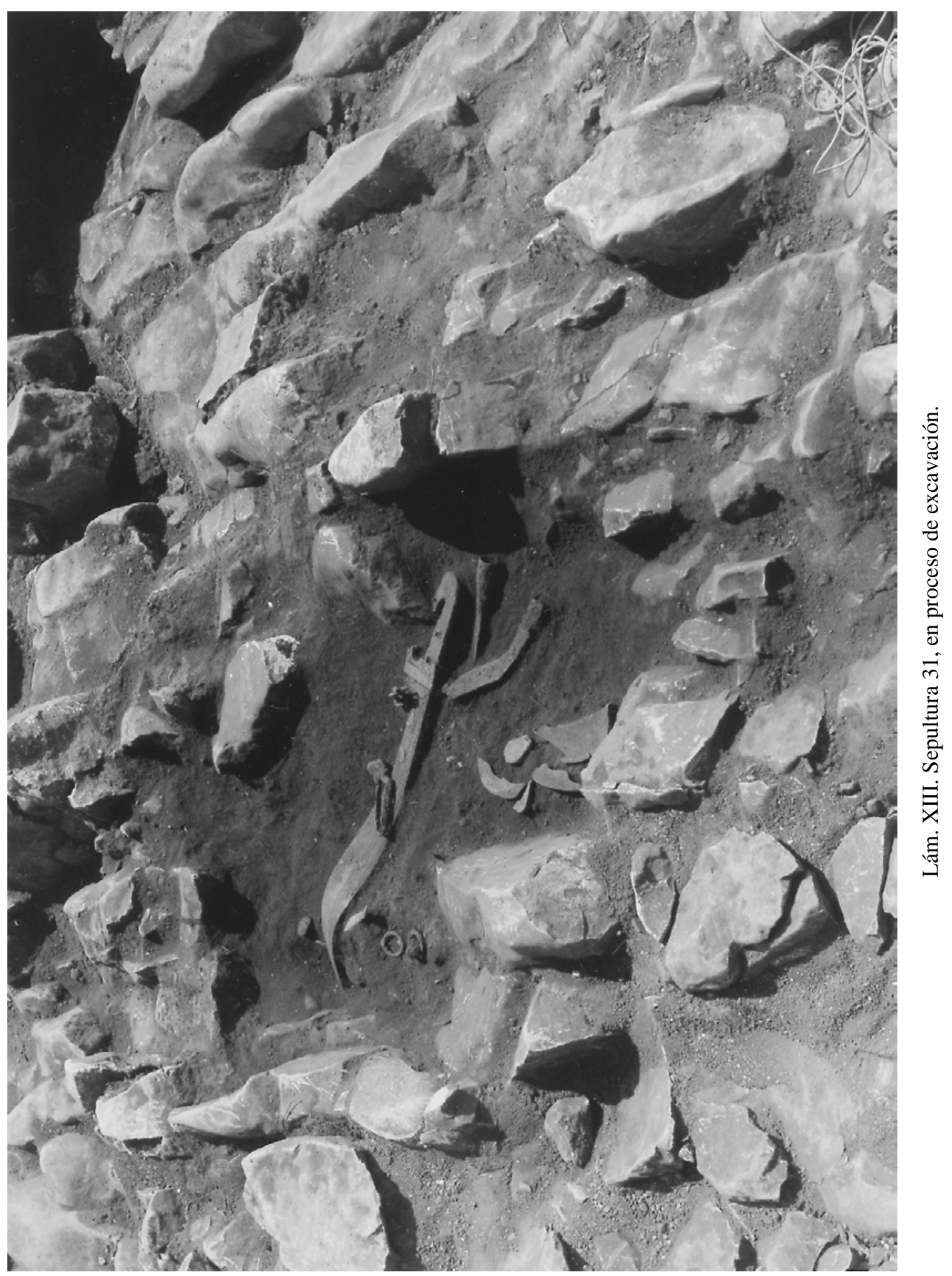




\section{MODELOS DE DEPOSICIÓN DE LAS ARMAS EN EL ÁREA DE LA SEPULTURA}

No hemos observado un patrón definido en cuanto a la deposición de las falcatas ni en el espacio de la sepultura ni respecto a otras armas. En cada sepultura se crea un «caso particular». En ocasiones se entremezcla con otras armas y el resto del ajuar funerario, sin adoptar ningún lugar preferente, como sería el caso de la sepultura 1 o 53; en otras se dispone en el centro de la mancha de cenizas, y a su alrededor se colocan las demás armas, como en la 31 (lám. XIII). La mayoría de las veces se deposita en posición horizontal, incluso cuando se coloca doblada, sepulturas $4,11,27$, etc. y en alguna ocasión aparece hincada en el suelo, como en la sepultura 6 o los fragmentos correspondientes a la zona de la punta de las sepulturas 29 y 53.

Puede tener otra arma cruzada sobre su hoja o aparecer completamente despejada: en el primer caso tenemos los ejemplos de la sepultura 11, que tenía la manilla de escudo en perpendicular sobre su hoja, o la sepultura 20, con los fragmentos de soliferrea en idéntica posición, o la sepultura 67, con la lanza cruzada sobre ella; respecto al segundo caso: las sepulturas 4,15 , etc.

La vaina aparece en ocasiones en su posición original, en otros casos los restos metálicos de esta pieza aparecen entre el resto de las armas o directamente sobre la hoja de la falcata.

Tampoco existe una orientación preferente a la hora de la deposición de las falcatas en la sepultura, encontrándose las más diversas orientaciones; ni siquiera siguen la orientación general de la sepultura.

Aunque no hayamos encontrado un patrón que se repita en cuanto a la colocación de la falcata, sí que podemos concluir que las armas, y por lo tanto las falcatas, no se arrojaban al interior de la sepultura de cualquier modo, sino que se depositaban con todo cuidado, con evidente intencionalidad, sin seguir, eso sí, un ritual establecido idéntico para todas las sepulturas.

Centrándonos en las armas de asta cabe distinguir entre el tipo de disposición que presentan los soliferrea enteros de la sepultura 1, enrollados entorno a la urna cineraria, o los fragmentos doblados que se cruzan sobre la falcata en la sepultura 20, disposición que creemos relacionada directamente con el aspecto de la inutilización ritual, como veremos más adelante, y las diferentes disposiciones que adoptaron el resto de las armas de asta: tomando como referencia la falcata encontramos lanzas depositadas en paralelo a ella, sepulturas 6, 11, 27 y 31; en perpendicular, sepultura 4, y 45; o en aspa, sepulturas 20 y 67. La lanza de la sepultura 5 se dispuso en paralelo al puñal de frontón (lám. XIV).

Esta variedad de disposiciones se entiende si tenemos en cuenta lo expuesto anteriormente: no hay un patrón rígido que determine la colocación de las armas, salvo la agrupación de todas ellas juntas, por lo que es lógico que entren en contacto unas con otras de las más diversas formas, en el sentido vertical o en el horizontal.

Tomando como referencia la urna, en los casos de las sepulturas 1 y 6, las armas de asta están dispuestas rodeándola.

Como caso excepcional hay que comentar el que la lanza de la sepultura 41 apareciera hincada en el suelo, en contacto con la hoja de la falcata, que se encuentra partida por la mitad.

Respecto a la orientación de lanzas y demás armas de asta, nos encontramos de nuevo con tanta variedad de orientaciones como armas depositadas, hecho que ya vimos sucede con las falcatas.

Entre las manillas de escudo encontramos la tendencia a cruzarlas sobre las falcatas, como en la ya mencionada sepultura 11 (lám. XV), o en la 53. No obstante este hecho no se repite sistemáticamente en todos los ajuares, apareciendo estas piezas en diversas formas de deposición, incluso en un caso aparece hincada de perfil. 
A pesar de no haber patrón de deposición sí podemos apuntar dos observaciones generales, válidas para todo el conjunto de armas: las armas se agrupan todas juntas, nunca aparecen dispersas en la mancha de cenizas, sino formando un paquete más o menos ordenado, mejor o peor dispuesto, situado en cualquier sector de la sepultura, pero siempre juntas; y otro hecho observado hasta la fecha es que nunca aparecen armas dentro de la urna, como ocurre en otras necrópolis.

\section{INUTILIZACIÓN DE ARMAS}

Son numerosos los casos en los que las falcatas han sido inutilizadas doblándolas en ángulo de $90^{\circ}$, como las falcatas de la sepultura 1 y 27 , o forzando el arma hasta juntar empuñadura y punta, como las piezas de las sepulturas 4,6 y 41 . La sepultura 53 presentaba la falcata partida en dos mitades, con la parte inferior además doblada y el filo hincado en el suelo, mientras la zona correspondiente a la empuñadura estaba dispuesta en horizontal.

También se aprecian melladuras intencionadas en las hojas, en el filo principal, de las falcatas procedentes de las sepulturas 1 y 53, que han recibido un fuerte golpe contra una superficie dura, posiblemente una piedra. El estado fragmentado e incompleto de algunas falcatas, unido al deterioro del metal impide apreciar si hay más hojas con filos mellados intencionalmente.

Contamos con otro caso que puede estar relacionado con la inutilización ritual, aunque no presenta las agresiones comunes: la falcata de la sepultura 11 tiene la punta redondeada (Cortell et alii, 1992, fig. 11, 1) y esta alteración es demasiado regular y cuidada para pensar en una rotura casual o pérdida del fragmento distal, tanto más cuanto esta pieza se conserva en buen estado. Deliberadamente se ha eliminado la capacidad punzante de la pieza, que por lo demás, no presenta otro tipo de inutilización al uso. ¿Qué motivo, sino ritual, puede llevar a recortar la punta de un arma?.

Hemos observado un hecho curioso: todas las falcatas que presentan decoración han sido sistemáticamente inutilizadas, casi con ensañamiento: rotas, dobladas sus mitades y con melladuras en el filo; en cambio contamos con algunas piezas que, aparentemente, no han sido inutilizadas y casualmente carecen de decoración, por ejemplo, las falcatas de las sepulturas 15 o 31. No se trata de que todas las falcatas sin decoración no hayan sido inutilizadas, sino que todas las que no lo han sido carecen de ella. ¿Por qué no se aplica el ritual a todas?. Parece haber una razón de índole práctico, añadida a la ritual, en la destrucción de las falcatas decoradas: evitar su saqueo. Sin embargo en el caso de las piezas sin decoración no parece que haya unidad de criterio, ni siquiera en razón del ritual.

Entre las armas de asta, es el soliferreum el que se presenta siempre inutilizado: en la sepultura 1 aparecen los dos enrollados alrededor de la urna, incluso los fragmentos de la sepultura 20 aparecen doblados, aunque el arma no aparece completa.

Lo mismo ocurre con los indet. solif/pil de las sepulturas 41, 69 y 70, a pesar de tratarse de fragmentos, algunos de ellos aparecen doblados, como si se tratara de partes de un arma previamente doblada.

Respecto a lanzas dobladas, sólo una de las dos con que cuenta la sepultura 4 aparece doblada de forma que la punta de la hoja se acerca a la base de la misma. Se trata precisamente de la lanza tipo 2, la más larga del par, pero no la más larga de la necrópolis, ya que mayor longitud tienen las lanzas de las sepulturas 35 y 67 y no estaban dobladas.

En cuanto a los escudos, sólo en el caso de la sepultura 27 la empuñadura está claramente inutilizada y su deformación no puede atribuirse a los efectos del calor de la pira, ni a una deposición forzada entre más armas en el área de la sepultura, ya que está doblada con una de las aletas contra el asidero, lo que prueba también que las empuñaduras se depositaban en la sepultura sin el cuerpo orgánico del escudo, que ya habría desaparecido durante la cremación. 


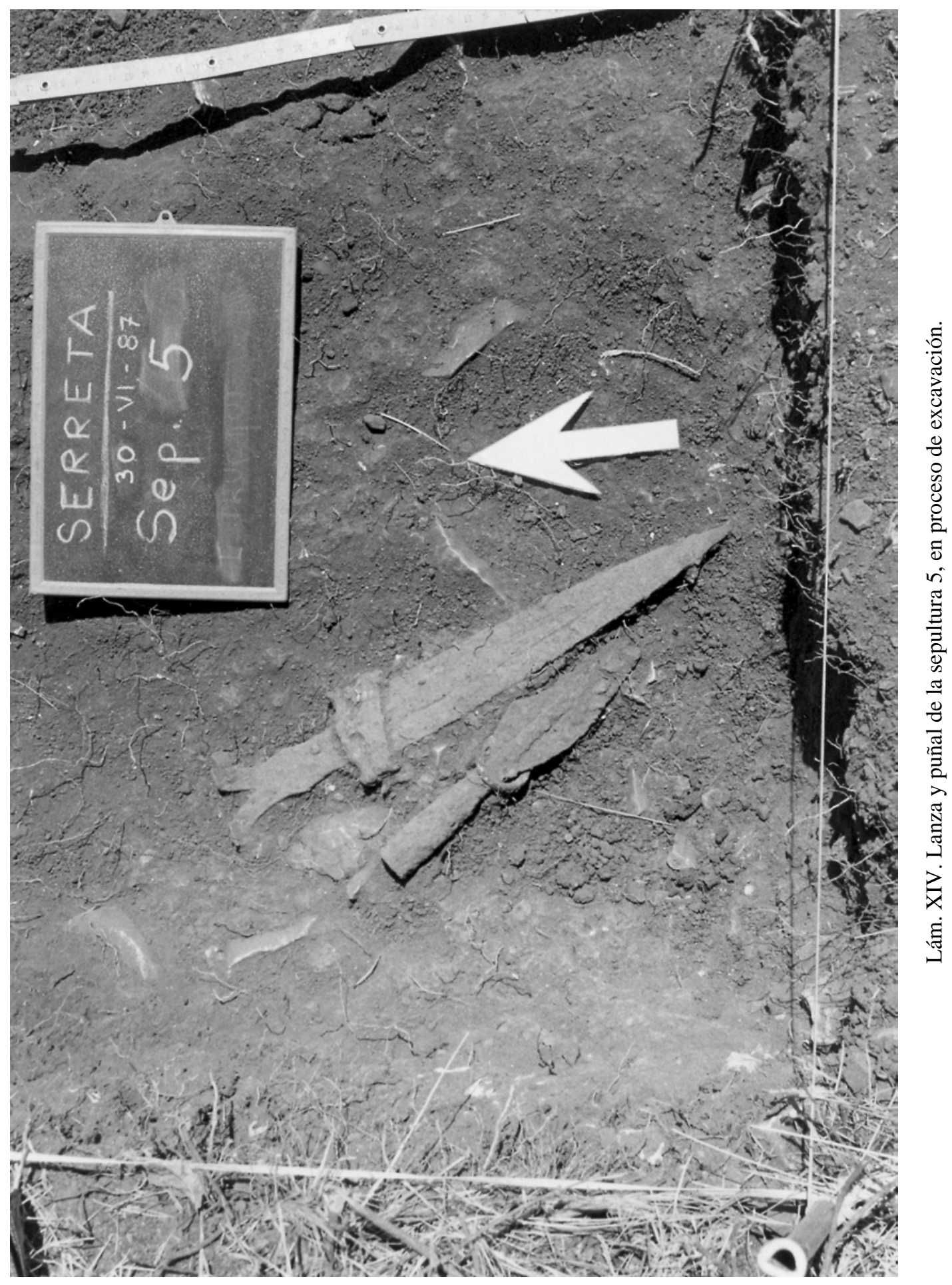




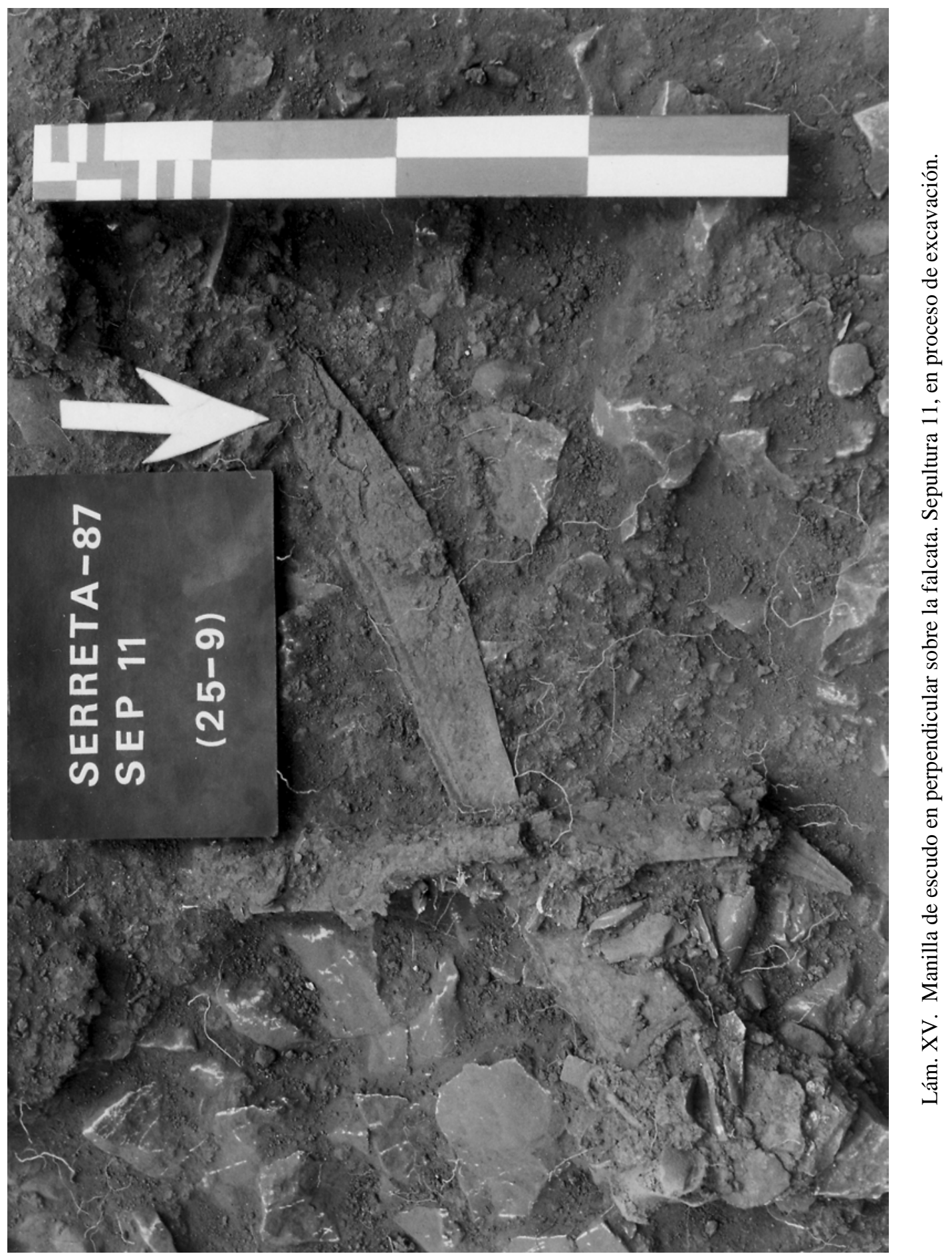


La empuñadura de la sepultura 1 también presenta una ligera deformación en su perfil así como una aleta un tanto retorcida sobre sí misma, pero puede deberse tanto al calor del fuego de la cremación como a su deposición forzada en la sepultura, entre los soliferrea enrollados, el pilum, y las demás armas. Las restantes no presentan deformaciones artificiales, o están tan fragmentadas que no es posible llegar a ninguna conclusión.

Tal vez la inutilización ritual de los escudos consistiera en su cremación, donde ya se perdía su parte fundamental, el cuerpo orgánico, y las empuñaduras no tuvieran que someterse, por regla general, al mismo proceso: quemado el escudo, éste ya no existe. No es el caso de las armas ofensivas, que no son compuestas, y donde lo que se inutiliza es el arma en sí misma, incluso después de quemada.

Del par de discos-coraza que aparecen en la sepultura 4, uno de ellos aparece intacto, cubriendo los restos de la cremación, pero el otro fue doblado en cuatro partes y retorcido.

La cuestión de la inutilización de las armas se ha tratado a menudo desde dos perspectivas: la ritual y la práctica. Analizando cada una por separado vemos que ninguna de las dos se cumple como norma general: si la razón fuera ritual, todas las armas deberían estar inutilizadas de alguna forma, y no es así, puesto que encontramos lanzas, falcatas o grandes manillas de escudo intactas; si la razón es práctica, evitar el saqueo de sepulturas, llegaríamos a la misma conclusión, debería haber más armas inutilizadas; si se trata de ganar espacio, es lógico que se doblen armas de considerable longitud como los soliferrea, lo cual ocurre en La Serreta, aunque no siempre en otras necrópolis, pero no lo es que se doblen algunas armas cortas como falcatas o lanzas.

Puede ser que la verdadera razón sea una combinación de ambas teorías, regulada por motivaciones que se nos escapan, de forma que en ocasiones se cumple y en otras no.

\section{ASOCIACIONES DE ARMAS}

Una vez realizado el estudio de las armas por categorías, se procede a la valoración e interpretación del conjunto para tratar de esclarecer cuestiones como:

- frecuencia de aparición de categorías y porcentaje sobre el total del conjunto;

- combinaciones de armas y frecuencia de aparición en sepulturas;

- posible coherencia funcional de los conjuntos depositados, a través del estudio de las asociaciones

- evaluación del conjunto de armas presente en la necrópolis, dentro de la evolución de la panoplia ibérica, y encuadre cronológico del mismo.

Como se aprecia en los gráficos (figs. 7 y 8) la falcata es el arma más representada en los ajuares que cuentan con armamento, seguida de las lanzas no arrojadizas.

En tanto que arma, esta pieza es símbolo de poder y riqueza, pero su elevado número, cuestión ilógica desde el punto de vista táctico donde tendrían que destacar numéricamente las lanzas, indica que se trata de un arma cargada de un valor añadido. Parece desprenderse una evidente intencionalidad de depositar este tipo de pieza entre el ajuar de una sepultura, aunque sea tan solo un fragmento de ella, la parte por el todo. Esta es la razón por la cual aparece en ocasiones como arma única del ajuar: parece ser la condición que ha primado en la deposición de la sepultura 43, donde sólo encontramos el tercio superior del arma, correspondiente a la empuñadura; o en la sepultura 74, donde se recuperó tan sólo una cartela profusamente decorada. Ninguna otra arma aparecía en ambas sepulturas, intactas, por otro lado.

Si tenermos en cuenta las piezas decoradas, que evidentemente destacan la capacidad económica de su poseedor, y concedemos un significado no casual a los motivos decorativos, 


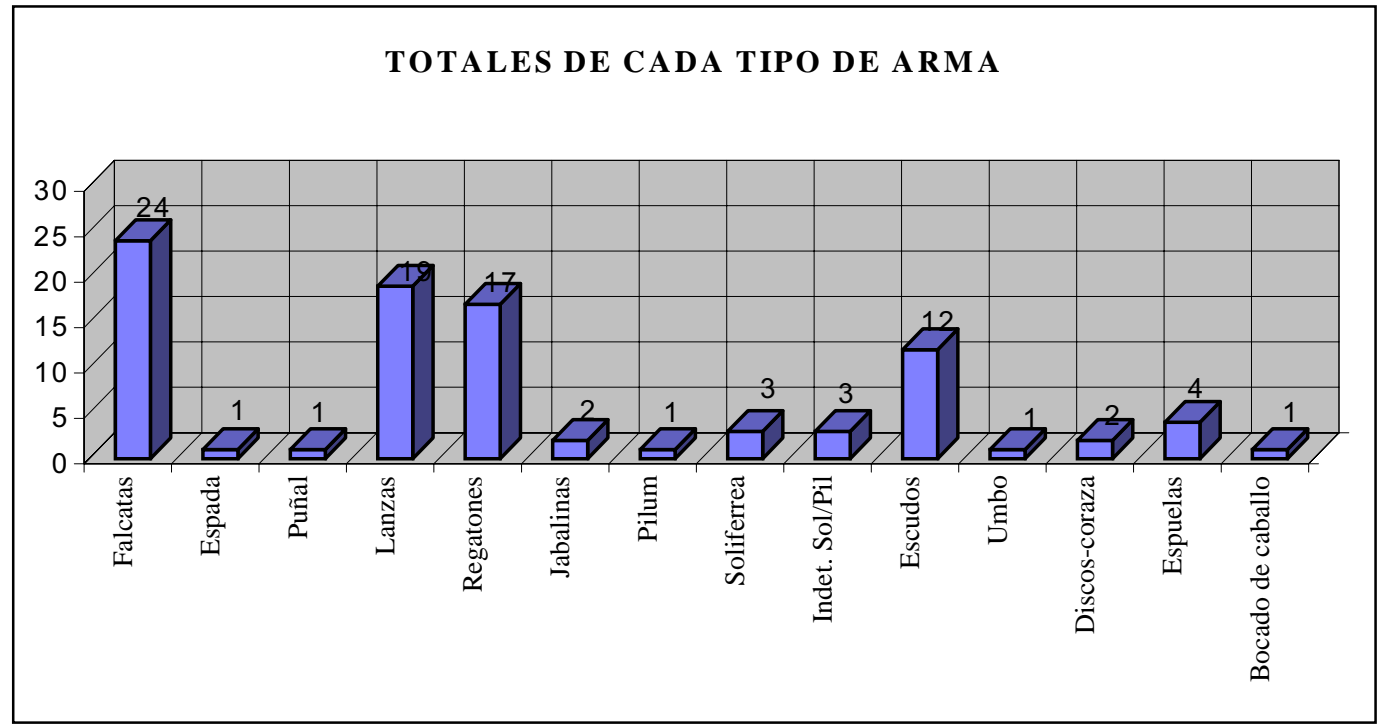

Fig. 7. Gráfica con los totales de cada tipo de arma.

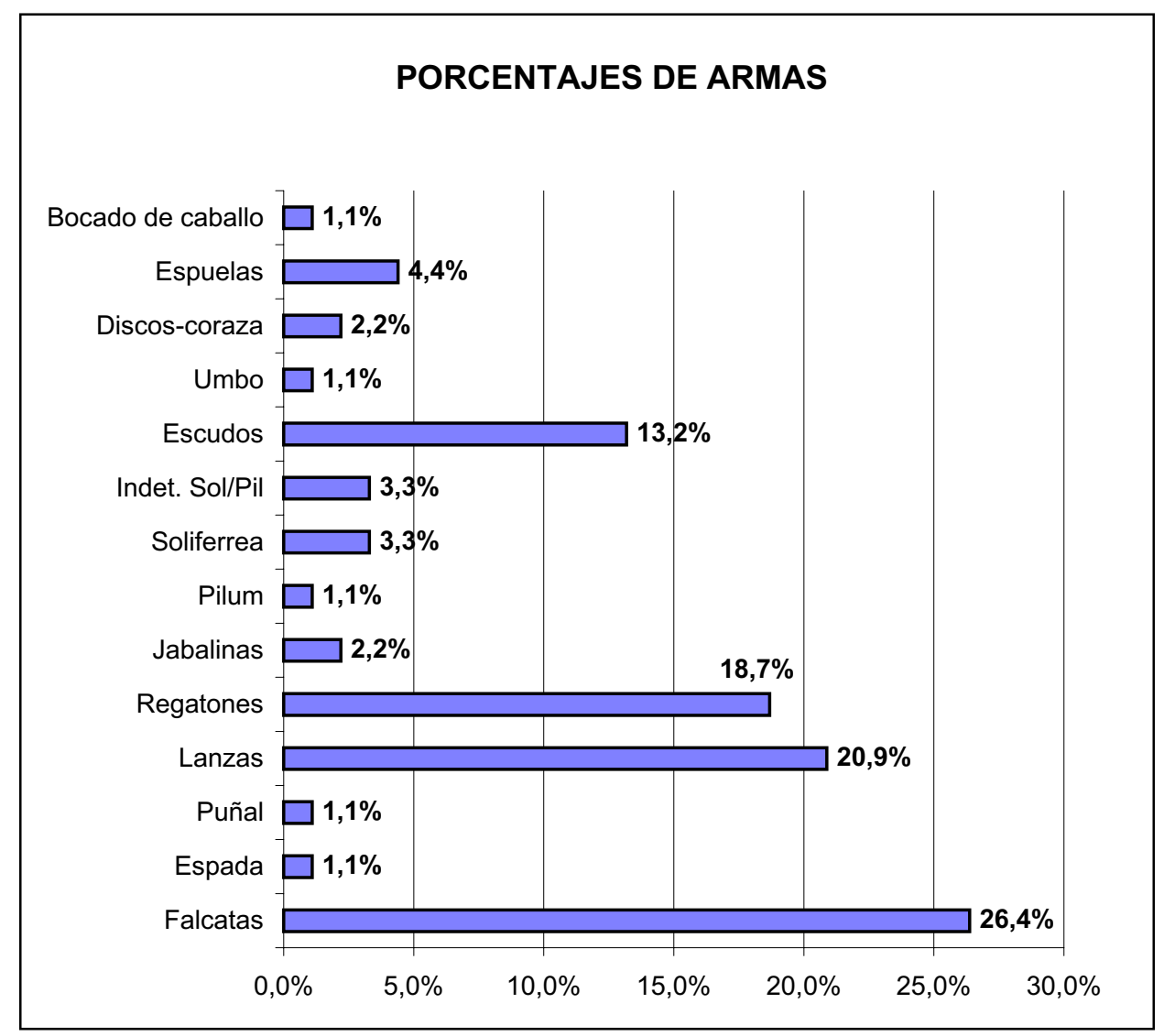

Fig. 8. Porcentajes de cada tipo de arma sobre el total del armamento. 
más allá de su valor ornamental, relacionándolos con el mundo de las creencias, como las adormideras o la hiedra de la falcata de la sepultura 53, la conclusión es que la falcata trasciende su condición de arma para convertirse en símbolo.

Si añadimos al total de falcatas, la espada y el puñal, el total de armas ofensivas cortas queda ligeramente superado por las 28 armas ofensivas largas.

Desde el aspecto funcional de las armas hay un predominio absoluto de las ofensivas, con el 78\% del total de armas, y dentro de éstas, el 63\% corresponde a las armas ofensivas largas, que son las más numerosas en la necrópolis destacando en porcentaje las empuñadas sobre las propiamente arrojadizas. y 10).

Las defensivas sólo representan el 16\% del total, y de éstas, el $80 \%$ son escudos (figs. 9

\section{PORCENTAJES DE ARMAS SEGÚN SU FUNCIONALIDAD}

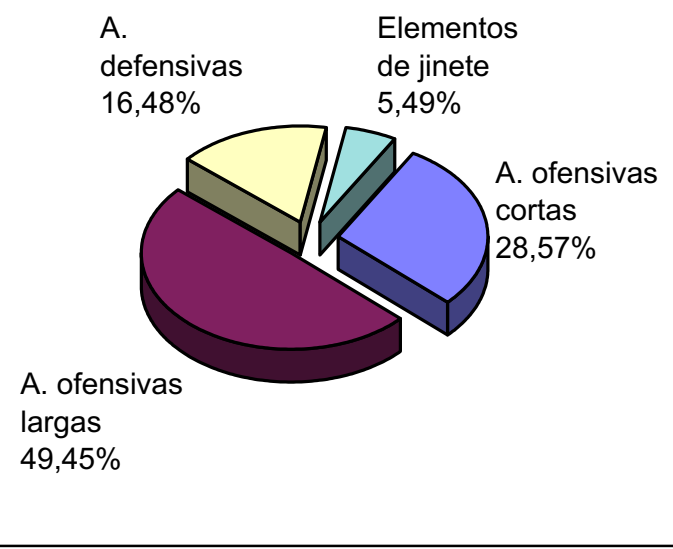

Fig. 9. Porcentaje de armas según su funcionalidad.

\section{PORCENTAJES DE ARMAS OFENSIVAS}

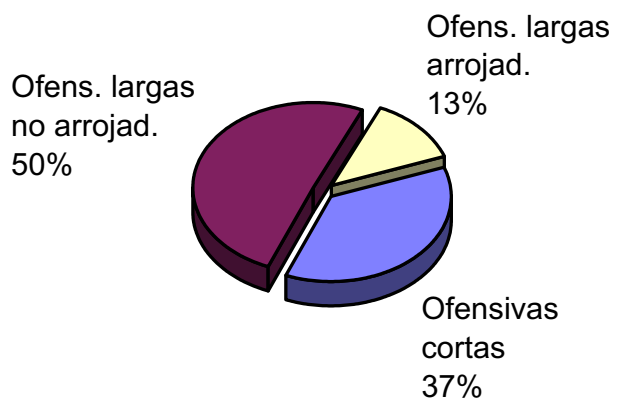

Fig. 10. Porcentaje de armas ofensivas. 
Del cuadro se desprende que la mayoría de las sepulturas presentan un conjunto de armas, más o menos completo, funcionalmente coherente (fig. 11). Son escasas las sepulturas que sólo aportan un arma y ésta es, en la mayoría de los casos, una falcata, entera o fragmentada.

Sólo en dos ocasiones aparece una lanza, sin más armas, lo que que resulta más lógico que el caso anterior, al tratarse del arma prioritaria en el combate y tal vez la primera en adquirirse, o la única. Además, este tipo de arma carece de la fuerte carga simbólica que se le atribuye a la falcata.

\begin{tabular}{|l|c|c|}
\hline COMBINACIÓN DE ARMAS & SEPULTURAS & FRECUENCIA \\
\hline Falcata/s & $15,22,43,74$ & 4 \\
\hline Falcata / lanza & $23,38,67$ & 3 \\
\hline Falcata / lanza / a. arrojadiza & 41 & 1 \\
\hline Falcata / lanza / escudo & $27,31,45$ & 3 \\
\hline Falcata / lanza / regatón / escudo & 29,72 & 2 \\
\hline Falcata / lanza / regatón / escudo / discos-coraza & 4 & 1 \\
\hline Falcata / lanza / regatón / a. arrojad./ escudo / espuelas & 1 & 1 \\
\hline Falcata / lanza / regatón / escudo / espuelas / bocado & 53 & 1 \\
\hline Falcata / regatón / escudo & 26 & 2 \\
\hline Falcata / regatón / a. arrojadiza & 69,70 & 3 \\
\hline Falcata / regatón / a. arrojadiza / escudo & $6,11,20$ & 2 \\
\hline Lanza & 51,80 & 1 \\
\hline Lanza / regatón & 35 & 1 \\
\hline Espada / regatón & 50 & 1 \\
\hline Puñal / lanza & 5 & 2 \\
\hline Regatones & 19,25 & \\
\hline
\end{tabular}

Fig. 11. Cuadro con las distintas asociaciones de armas, sepulturas donde aparecen y frecuencia.

Nunca es un arma defensiva la que figura como único tipo de armamento en el ajuar, a pesar de contar con dos casos en los que a esta categoría se la ha dotado de un sentido simbólico, como se explica más adelante.

El caso de los regatones solos o sin punta de lanza se trata en el apartado dedicado al estudio de estas piezas.

Como norma general las armas ofensivas cortas se asocian a armas ofensivas largas, empuñadas o arrojadizas y en el caso de panoplias más completas aparece también un arma defensiva, lo cual crea un conjunto realmente «operativo».

Las armas defensivas solo están presentes en panoplias completas, es decir, cuando ya existe una falcata y al menos un arma ofensiva larga, y nunca como arma única. No aparecen empuñaduras asociadas a otro tipo de arma ofensiva corta que no sea falcata, es decir, no existe en el caso de la sepultura 50 donde aparece una espada de frontón ni en la sepultura 5, con un puñal. 
En cuanto a su asociación con las armas ofensivas largas, ésta se da tanto con las empuñadas como con las arrojadizas, y cuando este tipo no está representado siempre aparece un regatón que indica su presencia (ver cuestión regatón-lanza).

Es la presencia del escudo lo que define como completa a una panoplia, ya que éste siempre está presente cuando las otras categorías de armas ya están representadas: nunca falta un arma ofensiva larga, o una corta.

La existencia de escudos totalmente orgánicos en asociaciones que ahora parecen incompletas, variaría estas observaciones, pero dejando de lado los supuestos, la mayoría de los conjuntos que aparecen en la necrópolis conforman una panoplia funcional sin escudo, aunque hay un elevado número de panoplias típicas.

No existen asociaciones funcionalmente absurdas, salvo los casos en que hay un exceso de armas, como en la sepultura 1, donde las tres armas arrojadizas, pilum y dos soliferrea, se suman a las dos empuñadas (Cortell et alii, 1992: 97), hecho que puede relacionarse con el deseo de expresar un estatus mediante la acumulación (Quesada, 1994); en las sepulturas 4 y 11 se produce el mismo fenómeno: doble arma defensiva, aunque en ambos casos una de las piezas está desempeñando un papel destacado, al margen del lote de armas. En la sepultura 4, además de la manilla de escudo, uno de los disco-coraza cubre los restos óseos, en la sepultura 11 ocurre lo mismo con el umbo (siempre que se considere como no perteneciente al escudo que aparece en la sepultura)

\section{CONCLUSIONES}

Por todo lo visto hasta ahora hemos de concluir que las armas depositadas en los ajuares funerarios de la necrópolis de La Serreta, sobre todo sus conjuntos, lejos de ser dispuestas de forma aleatoria, representan panoplias totalmente operativas, con las que un íbero podría entrar en combate. De las formas de éste también nos aportan detalles, a través de un estudio más pormenorizado que excede las intenciones del presente artículo.

En resumen, las armas presentes en esta necrópolis formarían parte de lo que F. Quesada llama la «panoplia generalizada» (1997: 611) en su propuesta de establecer una evolución de la panoplia ibérica. Ésta es la que comprende desde principios del s. IV a.C. hasta el último tercio del s. III a.C., aunque contemos con elementos propios de la "panoplia aristocrática» (último tercio del siglo VI a.C.- final del s.V a.C.), como los discos coraza de bronce de la sepultura 4, el umbo de bronce de la sepultura 11, o la espada de frontón de la sepultura 50, perduraciones de una panoplia antigua o variantes tardías.

\section{CRistina Reig Seguí}

Museo Arqueológico Municipal de Alcoy «Camilo Visedo Moltó».

\section{BILIOGRAFÍA}

Cortell, E., Juan J., Llobregat, E., Reig, C., Sala, F. y Segura, J.Ma. (1992): La necrópolis ibérica de La Serreta: resumen de la campaña de 1987. Estudios de Arqueología ibérica y romana. Homenaje a Enrique Pla Ballester. Serie de Trabajos Varios 89: 83-116. València.

CABRÉ DE MoRÁn, E y MoRÁn CABRÉ, J.A. (1979): Aportación al estudio tipológico de las espadas «Alcacer do Sal». Una nueva serie descubierta en la necrópolis de La Osera (Chamartín de la Sierra, Ávila. C.N.A. XV: 763-770. Lugo.

CuAdRADO DíAZ, E. (1963): Puñales de antenas en territorio ibérico. Zephyrus XIV: 17-27. Salamanca. 
CuAdrado DíAZ, E. (1987): La necrópolis ibérica de «El Cigarralejo» (Mula, Murcia) B.P.H. vol. XXIII. Madrid.

CUADRAdo DíAZ, E. (1989): La panoplia ibérica de «El Cigarralejo» (Mula, Murcia). Documentos. Serie Arqueología, 3. Murcia.

GRAU MIRA, I. (1996): Estudio de las excavaciones antiguas de 1953 y 1956 en el poblado ibérico de La Serreta. Recerques del Museu d'Alcoi 5, 83-116.

JuAn Moltó, J. (1988): El conjunt de terracotes votives del santuari ibéric de La Serreta (AlcoyCocentaina-Penáguila). Saguntum 21, 295-329.

Llobregat Conesa, E.; Cortell Pérez, E.; JuAn Moltó, J.; Segura Martí, J.Mª (1992): El urbanismo ibérico en La Serreta. Recerques del Museu d'Alcoi 1, 37-70.

Llobregat Conesa, E.; Cortell PÉReZ, E.; JuAn Moltó, J.; Olcina Doménech, M.; SegurA MARTí, J.Ma . (1995): El sistema defensiu de la porta d'entrada del poblat ibèric de La Serreta. Estudi preliminar. Recerques del Museu d'Alcoi 4, 135-162.

Miró SegurA, J.H. y ReIG SEguí, C. (1997): Los cubos de enmangue de lanzas y regatones ibéricos. Análisis y diagnóstico. Recerques del Museu d'Alcoi 6, 161-165.

Moltó GisBert, S.; ReIG SEguí, C. (1996): La sepultura 53 de la necròpoli ibèrica de La Serreta. Recerques del Museu d'Alcoi 5, 121-135.

Olcina Doménech, M.; Grau Mira, I.; Sala Sellés, F.; Moltó Gisbert, S.; Reig Seguí, C.; SEgura MARTí, J.Ma . (1998): Nuevas aportaciones a la evolución de la ciudad ibérica: el ejemplo de La Serreta. Los íberos. Príncipes de Occidente. Estructuras de poder en la sociedad Ibérica. Actas del Congreso Internacional. Barcelona, 1998. Fundación La Caixa. 35-46.

PRATS I DARDER, C. (1993): Procés de conservació-restauració d'un umbo ibèric de bronze del Museu d'Alcoi. Recerques del Museu d'Alcoi, 2. 141-147.

Prats I DArder, C.; Rovira I HortalÀ, M.C.; Miró I SegurA, J. (1996): La falcata i la beina damasquinades trobades a la tomba 53 de la necròpoli ibèrica de La Serreta d'Alcoi. Procés de conservació-restauració i estudi tipològic. Recerques del Museu d'Alcoi 5, 137-154.

Quesada SAnZ, F. (1992): Arma y símbolo: la falcata ibérica. Instituto de Cultura Juan GilAlbert. Alicante.

QUESADA SANZ, F. (1994): Riqueza y jerarquización social en necrópolis ibéricas: los ajuares. Homenaje a José Ma Blázquez, II, 447-466. Madrid.

QUESADA SANZ, F. (1997): El armamento ibérico. Estudio tipológico, geográfico, funcional, social y simbólico de las armas en la Cultura Ibérica (siglos VI-I a.C.) Monographies instrumentum 3.2 tomos. Éditions Monique Mergoil. Montagnac.

TARRADELL, M. (1968): Grafito ibérico de la comarca de Alcoy sobre campaniense A. Rivista di Studi Liguri, XXXIV, 1-3: 355-362.

VAQUERIzo GiL, D. (1990): Armas de hierro de raigambre meseteña, en la necrópolis de Los Collados (Almedinilla, Córdoba). Necrópolis Celtibéricas. II Simposio sobre los celtíberos. 225-229. Zaragoza. 